\begin{abstract}
The paper argues that Possession is to be decomposed into three distinct syntactic configurations, each associated with its own meaning. These include Temporary Location, represented as an ordinary small clause, the Part-Whole relation, which always has a complement structure within DP as its source, and an applicative structure ApplP, the source of inalienable possession, where humans are treated as special. The analysis we propose extends to English, but focuses on Palestinian Arabic, a language which overtly distinguishes a number of ingredients which in other languages enter into Possession less transparently: it is 'analytic' with respect to HAVE, it marks Temporary Location and Part-Whole relations by distinct prepositions, and it features a scope-marking poor agreement / rich agreement distinction. The picture which emerges is partly familiar and partly new. We argue that the subject in possessive clauses is a derived subject in the alienable, inalienable, and Part-Whole relations, but not necessarily in the non-human locative relation, where raising to specIP is governed by considerations of economy and variation in the morpho-syntax of agreement. We also argue that clausal possession has a DP as its source, but only on the Part-Whole construal, drawing on previous work on the DP-internal semantics of possession. Finally, the applicative structure, on our conception, may be basic, or derived by head-movement, as it is in English, and it may be headed by an overt preposition, or simply contain an abstract head, as it does in PA. If we are correct, the difference between HAVE and BE may further reduce to parametric realization of prepositions in ApplP. The analysis we develop leads to a new division of labor between phi-features and the triggers for A-movement, according to which phi-features exert their effect on syntax only from the interfaces. Whereas rich agreement fixes scope, visible at LF, the EPP, as such, is regulated only at PF.
\end{abstract}




\section{Deconstructing Possession}

Nora Boneh and Ivy Sichel

\section{Introduction}

The term 'possession' typically conflates a variety of notions. The relations which may be expressed by English HAVE, for example, stretch beyond inalienable and alienable possession, in (1a-c), to include also Temporary Location of various sorts, in (1d-f):

(1) a. The tree has many branches

b. John has three kids

c. John has three blankets

d. Mary has the car

e. John has three blankets on him

f. The tree has three nests *(in it)

The grammatical realization of these relations is governed by several conditions having to do with whether the possessee is definite, whether the possessor DP denotes a human, and whether the head noun denotes a function. Our goal here is to identify the underlying syntactic structures and the procedures which derive the semantic relations with which they are associated. Following up on the syntactic decomposition in Hornstein et al. (1995), and bringing it to bear on the semantic literature on possession within DP (Partee 1999; Partee \& Borschev 2003; Dowty \& Barker 1992; Guéron 2006; Dobrovie-Sorin 2005; Heller 2002), we decompose the term Possession into two independent notions, each associated with its own syntax: a Part-Whole 
relation, which we take to be broader than inalienable possession, and a Temporary Location relation.

The focus of our discussion is Palestinian Arabic (henceforth PA). PA is a HAVE-less language, and as such can be said to be analytic with respect to the ingredients which enter into HAVE (according to Freeze 1992, Kayne 1993). The relative transparency observed in PA enables us to trace the underlying syntax and conditions in the derivation of sentences associated with the various semantic relations in (1). PA also features a number of additional characteristics which make the syntactic details in the deconstruction of possession more readily tractable than in other languages. First, it overtly distinguishes Part-Whole and Temporary Location by choice of preposition, and second, it features both rich and poor agreement paradigms, enabling us to isolate movement for the sole purpose of EPP checking (Holmberg 2000; Bailyn 2004; Biberauer \& Roberts 2008). In conjunction with the absence of a null expletive, we distinguish several types of PP-fronting, and in particular the general fronting of all locative PPs from the fronting operation which treats humans as special, the syntactic source of alienable possession.

We argue, in the spirit of Hornstein et al. (1995), that Temporary Location is syntactically distinct from Part-Whole. Agreeing that Temporary Location has an ordinary Small Clause as its source, we depart from that proposal in our analysis of Part-Whole as represented only at the level of DP, where the Part is a noun denoting a function and the Whole is its argument. In this respect, we agree with previous claims in the literature (Kayne 1993, Szablosci 1983, 1994) that clausal possession is derived by raising from a DP source, but we restrict the DP source to the Part-Whole relation. The typology of PP-fronting operations we develop leads us to an account of the human / non-human division in terms of an underlying stative applicative structure (Pylkkänen 2002/2008 Cuervo 2003), licensed in the absence of a lexical verb. We 
argue for a raising-to-SpecIP analysis in PA (and by extension, English) alienable and inalienable constructions, and that PA and English differ with respect to the derivation of locatives (the English (1e-f)). Whereas PA has movement here too, English doesn't, a difference we derive from the interaction of Economy (Collins 1997) and the nature of agreement. Making use of the proposal that obligatory copular BE is the reflex of domain extending head-movement (Den Dikken 2006), we argue that the difference between BE and HAVE in the expression of possession has to do only with the realization of the preposition within the applicative structure, as an applicative head or as part of its specifier. In the course of the discussion, we also show that rich agreement in PA has interpretive consequences, visible at LF, while the EPP, as such, is regulated only at PF (Landau 2007).

The paper is organized as follows. After completing our introduction with the presentation of basic Palestinian Arabic data, we argue in the first part of the paper (sections 2-3) that the Part-Whole and Temporary Locative construals are associated with distinct syntactic structures. Our main evidence comes from asymmetries in word-order and compatibility with rich agreement on the verb. In the second part of the paper (sections 4-7), the focus shifts to the poor agreement paradigm, the domain of existentials. Section 5 further develops the syntax of Temporary Location and Part-Whole in configurations in which constituents other than the subject DP check EPP, and section 6 proposes that restrictions revolving around the human nature of the possessor have as their source an applicative structure. Section 7 returns to our starting point, English possessive HAVE. 


\subsection{Prepositions, Part-Whole, and Temporary Location}

Palestinian Arabic (the urban dialect) ${ }^{1}$, like other Semitic languages, does not have an auxiliary verb HAVE. Furthermore, in the present tense, the copula is null. ${ }^{2}$ Possession, existential and locative constructions are expressed with prepositional predicates. ${ }^{3}$ Importantly, the choice of preposition plays a crucial role in the distinction between Part-Whole and Temporary Location.

The distribution is particularly clear with inanimate noun phrases, where we observe complementary distribution. There is one preposition used to mark Part-Whole relations: la'to', ${ }^{4}$ this is exemplified in $(2 \mathrm{a}, \mathrm{c})$. Temporary Locative relations are marked by a variety of locative prepositions in $(2 b, d)$.

a. la-əš-šajara

to-the-tree branches many

'The tree has many branches.'

b. Sind əš-šajara Gru? ktar

at the-tree branches many

'Near the tree are many branches.'

c. la-əS-Sabra šok ialiil

to-the-cactus thorns few

'The cactus has few thorns.'

\footnotetext{
${ }^{1}$ Non-IPA phonetic symbols used in the transcription of the examples:

$\mathrm{H}$ : Pharyngeal voiceless fricative (ح)

T: Pharyngealized voiceless dental stop (b)

S: Pharyngealized voiceless dental fricative (ص)

R: Velar voiced fricative $(\dot{\varepsilon})$

${ }^{2}$ There appears to be some dialectal variation as to the availability of an overt copula in the present tense, within the Palestinian dialects.

${ }^{3}$ cf. Ouhalla (1998) for an analysis of Moroccan Arabic and the role of prepositions in possession.

${ }^{4}$ The preposition $l a$ - is in many ways equivalent to the English preposition to. Both are used as introducing goals and benefactives, and as directional prepositions.
} 
d. jamb əS-Sabra fiih $^{5}$ wardaat

beside the-cactus FIIH flowers

'Beside the cactus there are flowers.'

With human possessors, in (3), the distinction is to some extent blurred. Kinship relations and

body-parts are related to a human possessor via the preposition $l a-$, but the locative preposition

Sind 'at' can appear both in the case of kinship relations and temporary location (for some

speakers it is dispreferred with body-parts).

a. la-mona $\quad$ Panf Tawil / tlat ulaad

to-Mona nose big / three kids

'Mona has a big nose / Mona has three kids (she is their mother).'

b. $\quad$ Sind mona ktaab / tlat ulaad

at Mona book / three kids

'Mona has a book / Mona has three kids (she is their mother or babysitter).'

In (3b), Mona can be understood to be the mother of three kids or to be, say, their babysitter. The latter option is not an available reading of (3a), with $l a-(4)$. In other words, while la- remains restricted to Part-Whole, Sind with a human possessor can equally denote Part-Whole. ${ }^{6}$

\footnotetext{
${ }^{5}$ These examples show that the prepositions la- and Sind pattern differently from the locative preposition jamb 'beside', only with the latter the particle fiih is obligatory. Similarly in (i) with e.g. Sala 'on', wara? 'behind' and other locative prepositions.
a. $\quad$ Gala 2 l-that fiih šaršaf
on the-bed FIIH blanket
'On the bed there's a blanket.'
b. wara? al-kursi fiih Tawle
behind the-chair FIIH table
'Behind the chairs there's a table.'

This contrast will be discussed in section 6 . For the meantime, we wish to establish a terminological distinction between the prepositions. Henceforth locative preposition other than la- and Sind will be referred to as 'true/pure' locative prepositions.
} 
Deconstructing Possession

\begin{tabular}{|c|c|c|c|c|}
\hline Sind mona & I & \#la-mona & tlat ulaad & kul yom \\
\hline at Mona & / & to-Mona & three kids & every day \\
\hline
\end{tabular}

\section{Word Order Asymmetries}

Our first piece of evidence for a structural distinction between the Part-Whole and Locative construal comes from asymmetries in subject position originally observed by Hornstein et al. (1995, exx. 15-17). We begin by showing that in PA the asymmetry in the position of the subject is marked by choice of preposition.

\subsection{Cross-linguistic Parallelisms}

Hornstein et al. (1995) show that constructions containing expletive there allow both the PartWhole and Locative readings (5a, 6a, 7a, 8a), whereas a preverbal indefinite is restricted to the Locative construal, in (5b). (6b), (7b), and (8b) necessarily denote a Part-Whole relation, and are accordingly ungrammatical:

(5) a. There were ten kids in the building

b. Ten kids were in the building

(6) a. There were ten stories in the building

b. $\quad *$ Ten stories were in the building

\footnotetext{
${ }^{6}$ In locative copular sentences, the preposition Sind simply serves to physically locate the referent of the subject DP within the referent of the DP inside the PP:

(i) 1-ulaad Sind mona the-kids at Mona 'The kids are at Mona's (house).'

In this respect, the preposition Find is no different than pure locative prepositions.
} 
Deconstructing Possession
a. There were ten provinces in Canada
b. $\quad *$ Ten provinces were in Canada
(8) a. There is a long coastline in Panama
b. *A long coastline is in Panama

The contrast follows from Hornstein et al.'s (1995) analysis, where it is argued that the indefinite has a distinct syntactic status in each case. In the underlying structure of the Locative construal, the indefinite is the subject of a Small Clause and the preposition is the head of a predicative PP. As an underlying subject, the indefinite raises via NP-movement to the matrix subject position in the usual way, in (9a-b). The indefinite on the Part-Whole construal is the predicate of the Small Clause, and takes as its argument the Whole DP $(9 \mathrm{c}){ }^{7}$ As a predicate, the indefinite is not expected to raise to matrix subject position, in $(9 \mathrm{~d})$ :
a. $\mathrm{BE} \quad[\mathrm{sC} \mathrm{DP} \quad \mathrm{PP}]$
(Hornstein et al. 1995)
b. $\mathrm{DP}_{1} \quad \mathrm{BE} \quad\left[\begin{array}{lll}\mathrm{sc} & \mathrm{t}_{1} & \mathrm{PP}\end{array}\right]$
c. $\quad$ BE P $\left[\mathrm{sc}_{\mathrm{SP}} \mathrm{DP}_{\text {Whole }} \mathrm{NP}_{\text {Part }}\right]$
d. $\quad * \mathrm{NP}_{1} \quad \mathrm{BE} \quad\left[\mathrm{sC} \mathrm{PP}_{\text {Whole }} \mathrm{t}_{1}\right]$

We return to this analysis with refinements after presenting further data from Hebrew and PA.

A similar alternation is observed In Hebrew. Although it is generally SVO, Hebrew has a class of copulas which, in their uninflected form, precede an indefinite subject, in (10). Similar to the English existential, both construals are possible in (10):
a. eyn
šaloš yeladot ba-binyan

BE.NEG

three girls in.the-building

\footnotetext{
${ }^{7}$ Following Freeze (1992) and Kayne (1993), Hornstein et al. (1995) argue that the preposition does not form a constituent with the Whole DP, it is outside the Small Clause (9c).
} 
Deconstructing Possession

'There aren't three girls in the building.'

b. eyn šaloš komot ba-binyan
BE.NEG three stories in.the-building
'There aren't three stories in the building.'

Again, as in English, only on the Locative construal can the indefinite appear in pre-copular position:
a. šaloš yeladot
eyn-an
ba-binyan
three girls
BE.NEG-3PL.F in.the-building
'Three girls aren't in the building.'
b. *šaloš komot eyn-an ba-binyan
three stories BE.NEG-3PL.F in.the-building
‘*Three stories aren't in the building.'

The same pattern is attested in PA:

a. tlat ulaad

kaanu

fi-əl-@amaara

three kids small

WERE.3PL in-the-building

'Three kids were in the building.'

b. *tlat Tawabe? $\quad$ kaanu fi-əl-Yamaara
three stories $\quad$ WERE.3PL in-the-building
'*Three stories were in the building.'

In PA, the syntactic distinction is marked, in addition, by choice of preposition. In all the examples considered so far, Part-Whole is the only construal available for the head noun: stories and buildings; provinces and countries; coastlines and countries. The relevance of choice of 
preposition for syntactic configuration is better observed when the head noun can, in principle, be interpreted either as a Part of the Whole denoted by the indefinite, or as standing in some temporary location. For example, branches may be part of a tree, or may be located in relation to the tree. On the locative construal, three branches can surface in preverbal position, as expected, just like three nests, which is necessarily locative.
a. tlat Sru?
kaanu
Sal-əš-šajara
three branches
WERE.3PL
on-the-tree
'Three branches were on the tree.'
b. tlat ९šuuš kaanu Sal-əš-šajara
three nests WERE.3PL on-the-tree
'Three nests were on the tree.'

The preverbal construction in (13) is based on temporary-locative syntax, and is, furthermore, restricted to a locative preposition. Part-Whole, on the other hand, is restricted to la- (ex. 2). The distinction is reflected syntactically: when three branches is associated with la-, it is construed as a Part, and is accordingly excluded from pre-verbal position. This also holds for nests, which do not qualify as parts of a tree, and can only be construed as temporarily located in relation to a tree. Since la-blocks locative syntax, three nests is excluded from preverbal position when associated with $l a-$ :
a. *tlat Sru?
kaanu
la-ə̌̌-šajara
three branches
WERE.3PL
to-the-tree
‘*Three branches were to the tree.' 
Deconstructing Possession

$\begin{array}{llll}\text { b. } & \text { *tlat } \text { 〔šuuš } & \text { kaanu } & \text { la-əš-šajara } \\ & \text { three nests } & \text { WERE.3PL } & \text { to-the-tree }\end{array}$

‘*Three nest were to the tree.'

(13) - (14) show that the association of preposition and interpretation is represented in the syntax: a locative preposition is associated with locative syntax, whereas $l a$ - is associated with Part-Whole syntax. We have shown, in addition, that the association of preposition and syntactic configuration is direct, above and beyond the type of noun involved. Depending on choice of preposition, three branches will be associated with locative syntax or Part-Whole syntax where choice of preposition correlates with syntax. While in PA Part-Whole and temporary location are marked overtly, the syntax is identical to what we find in English and Hebrew. Conversely, cross-linguistic syntactic identity provides strong motivation for our claim that choice of preposition in PA is not merely a lexical matter.

\subsection{The DP Source of Part-Whole}

We have shown that cross-linguistically, the syntax individuates the Locative relation. Although Hornstein et al.'s analysis accounts for the asymmetry in word order, the Small Clause in (9c) seems to be ad hoc since no other predications are derived from it. In particular, copular BE does not produce predications where the Whole is in matrix subject position.

(15) a. *The book is the first chapter

b. $\quad *$ The tree is many branches

c. $\quad$ *The building is ten stories

d. ?*The ring is gold 
The ungrammaticality of the sentences in $(15)^{8}$ is unexpected, since nothing seems to prevent the Whole DP from moving to the preverbal subject position.

We agree with the basic intuition in Hornstein et al. (1995) that the Whole is an argument of a predicative Part, to be distinguished from the underlying analysis of the Locative construal. Here we argue that Part-Whole is linguistically encoded only at the level of DP, and that its distribution in clauses follows from general syntactic mechanisms, to be demonstrated throughout based on the syntax of PA. To the extent that the relation is independently individuated within DP, an analysis which takes DP as its starting point should be preferred on general grounds of parsimony.

Cross-linguistically, Part-Whole is represented within DP, where $\mathrm{N}^{\circ}$ is a functional noun and the Whole is its argument. This idea is not new, and has emerged in various studies of DP (Dowty \& Barker 1992; Vergnaud \& Zubizaretta 1992; Partee 1999; Heller 2002; Partee \& Borschev 2004; Jensen \& Vikner 2004; Dobrovie-Sorin 2005). The idea that clausal possession has a DP source is also not new (Szabolcsi 1983, 1994; Kayne 1993). In these studies, however, no distinction is drawn between Part-Whole and Temporary Location and the syntactic claims apply uniformly to all possessive clauses. Here we claim that possession does have a DP as one of its sources, and that the DP is restricted to Part-Whole; Temporary Location proceeds from a conventional Small Clause. Our contribution will be to incorporate the DP source of Part-Whole into a general analysis of 'clausal possession' for which we find particularly clear evidence in PA.

\footnotetext{
${ }^{8}$ Larry Horn has pointed out to us that $(15 \mathrm{c}-\mathrm{d})$ are good when interpreted as exhaustive constitution. We agree with these judgments. Hornstein et al. (1995) assimilate the Part-Whole relation to exhaustive constitution as developed in Bruge (1972). Here we remain agnostic as to whether Part-Whole may have roots in exhaustive constitution, and note that these relations do not appear to have the same distribution across the HAVE and BE paradigms, cf. The ring has gold in it vs. The ring is gold.
} 
The syntactic realization of Part-Whole is independently attested in DP. In English, for example, only a functional noun denoting a Part can take a Whole as its complement:

$$
\left[\mathrm{DP} \ldots . .\left[\mathrm{NP} \mathrm{N}^{\circ} \text { function } \mathrm{DP}_{\text {argument }}\right]\right]
$$

(17) a. the tree's branches

b. the branches of the tree

c. the tree's nest

d. *the nest of the tree

Thus, the frame of DP does not allow mere possessors or locations, in (17d), whereas the 's genitive is indifferent to this distinction. This appears to be systematic (Dowty \& Barker 1992):
a. Panama's coastline
/ the coastline of Panama
b. the book's first chapter
/ the first chapter of the book
c. the table's edge
/ the edge of the table
d. the mayor's wife
/ the wife of the mayor
e. John's uncle
/ an uncle of John
f. the cat's right ear
/ the right ear of the cat
g. Mary's car
/ * * the car of Mary

We use Part-Whole to cover the variety of relations in (18), since it is broader than what is sometimes called 'inalienable' possession, encompassing also inanimate Wholes, body-parts, kinship and social relations. ${ }^{9}$

Preliminary evidence for the necessary source of Part-Whole within DP is also attested in PA. We have shown that Part-Whole in clausal possession is restricted to the preposition la-

\footnotetext{
${ }^{9}$ Whether and to what extent social relations and kinship are involved in Part-Whole/inalienable relations seems to be language dependent (cf. Baron et al. 2001; Heine 1997).
} 
(with non-humans). $l a$ - is also found within DP, and quite pervasively. Within DP it may denote a variety of relations, ranging from Part-Whole to contextual association not necessarily involving possession (cf. Jensen \& Vikner 2004 for the classification of these relations):

a. saHel-a la-Panama

coastline-3SG.F to-Panama

'The coastline of Panama'

b. malik-a la-d-dawle

king-3SG.F to-the-country

'The king of the country'

c. sama-ha la-yafa

sky-3SG.F to-Jaffa

'The sky of Jaffa'

d. Šabab-a la-mona

youth-3SG.F to-Mona

'Mona's guys'

(20) a. kaan saHel Tawil la-panama

WAS.3SG coastline long to-Panama

'Panama had a long coast line.'

b. *kaan šabab la-mona

WAS.3SG guys to-Mona

c. *kaan sama Razra? la-yafa

WAS.3SG sky blue to-Jaffa 
Given the representation of Part-Whole as a functional noun denoting the Part and the Whole as its argument, and since this is the only function-argument relation with non-derived nouns, we derive the restriction of clausal la- to Part-Whole based on the syntax of extraction in conjunction with the most basic formulation of the ECP: only an argument can be extracted from DP (cf. Godard 1992). Therefore, to the extent that la-DP must be external to its containing DP (see section 5.1), la- in clausal possession configuration is restricted to Part-Whole.

Independent motivation for the analysis of Part-Whole in (16) as represented at the level of DP is provided by the pattern of modification. la-DP can directly modify the head noun, whereas Sind-DP modification is always introduced by a relative clause. In the latter, the presence of Pilli is obligatory, which signals the introduction of an embedded clause. ${ }^{10}$

a. ulaad-ha la-mona šatriin

kids-3SG.F to-Mona smart

'Mona's kids are smart.'

b. $\quad$ ol-ulaad (2illi) Sind mona šatriin

the-kids that at Monart

'The kids that are at Mona's are smart.'

The necessary introduction of a relative clause with Sind-modification, and the absence thereof with $l a$-modification supports our claim that $l a$-DP is introduced within the basic DP, as an argument of the functional noun. Sind-DP, in contrast, is always predicative in the specific sense that it occurs in a clausal structure, outside of its DP argument. This is schematized in (22):

\footnotetext{
${ }^{10} l a$-DP with a definite requires doubling.
} 
Deconstructing Possession
a. $\quad$ BE $\quad[\mathrm{DP}$ big nose $[\mathrm{pP}$ to-Sami $]$
b. $\quad \mathrm{BE} \quad[\mathrm{SC}$ [three nests] [PP by the tree]]

\section{Agreement Asymmetries}

The proposal that only on the Locative construal the indefinite qualifies as an independent DP is further supported by the pattern of agreement. Here we show that in the post-copular DP-PP order, the indefinite in the temporary Locative construal requires rich agreement while on the Part-Whole construal it is incompatible with rich agreement.

Like many other Semitic and Celtic languages, agreement in PA may be rich or poor (see, for example, McCloskey \& Hale 1984 for Irish, Rouveret 1991 for Welsh, Fassi Fehri 1993 for Standard Arabic, and Hoyt 2000 for PA). Rich agreement specifies the full array of gender, number, and person features associated with the subject DP. Poor agreement in PA means that the verb rigidly specifies $3^{\text {rd }}$ person, singular, masculine, regardless of the phi-features associated with DP. ${ }^{11}$ Poor agreement is restricted to a subset of intransitive unaccusative verbs, including the copula. While agreement with transitive and unergative verbs is necessarily rich, some intransitive unaccusatives allow rich agreement or poor agreement. Poor agreement is further restricted by word order. PA allows both Subject-Verb and Verb-Subject orders, with poor agreement restricted to indefinite post-verbal subjects; regardless of verb type, a preverbal subject always shows rich agreement. The interaction of these conditions is illustrated in (23) with unergative sleep, and in (24) and (25) with unaccusative finish and arrive:

\footnotetext{
${ }^{11}$ PA differs, in this respect, from Standard Arabic, where poor agreement marks gender, but not number.
} 
(23)

a. tlat ulaad naam-u fi-l-bet

three children slept-3PL in-the-house

'Three children slept in the house.'

b. *tlat ulaad naam fi-l-bet

three children slept.3SG in-the-house

c. naam-u ulaad fi-l-bet

slept-3PL children in-the-house

d. *naam ulaad fi-l-bet

slept.3SG children in-the-house

(24) a. tlat baskot xils-u

three biscuits finished-3PL

'Three biscuits were consumed.'

b. *tlat baskot xiles

three biscuits finished.3SG

c. xils-u tlat baskot

finished-3PL three biscuits

'Three biscuits were consumed.'

d. xiles tlat baskot

finished.3SG three biscuits

'There were consumed three biscuits.'

(25) a. tlat ulaad biyuSal-u Sa-l-bet

three children arrive-3PL to-the-house

'Three children arrive at the house.' 
Deconstructing Possession

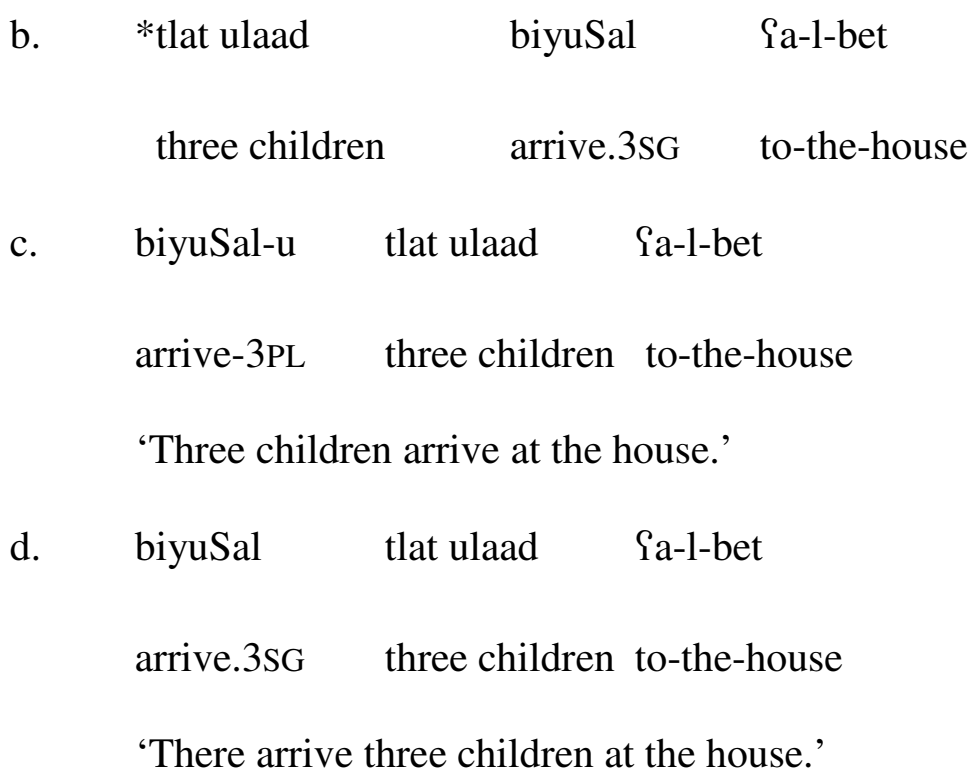

Crucially, an unaccusative verb can fail to agree just in case DP is indefinite and post-verbal. The poor agreement configuration in PA is similar, in a way, to languages such as French, Norwegian, and Swedish, which have pronominal (rather than locative 'there' type) expletives in subject position.
a. Il est venu quelques hommes
EXPL be.PRES.3SG came some men
'There came some men / some men came.'

b. Det er nett kome nokre gjester (Norwegian, from Afarli 2007)

it is just come.sG some guests

'Some guests have just arrived'

Mohammad (2000) argues that PA sentences like (24d)-(25d) have a null pronominal expletive. This is certainly an attractive analysis, as it places PA poor agreement on a par with French and Norwegian. Our study of PP-fronting in existentials in sections 4-6 demonstrates, however, that EPP is always checked by an overt category, by either Merge or Move. This leads us to reject the 
null expletive analysis, and to pursue an alternative in which the sole requirement imposed by poor agreement is EPP-checking; EPP is regulated only at PF (Landau 2007); movement at PF delivers Total Reconstruction (Sauerland \& Elbourne 2002) and the existential interpretation of (24d)-(25d). As we show shortly below, the interpretive effects of agreement, rich vs. poor, are more dramatic than the null expletive analysis would lead one to expect.

Returning to possession, we have shown above that an indefinite on the Locative construal can appear either in the canonical pre-copular position, or postverbally, following the copula. Focusing now on the post-copular DP-PP configuration, the relations are discriminated by choice of agreement. While Part-Whole is incompatible with rich agreement, Temporary Location requires rich agreement. The Part-Whole construal of the relation between a tree and its branches is guaranteed in (27) by the preposition $l a$ - and agreement is degraded. In (28), where the relation between a tree and three nests is necessarily Temporary Location, rich agreement is obligatory:

a. kaan la-əš-šajara

WAS.3SG five branches to-the-tree

'The tree had five branches.'

b. $\quad$ ?? kaan-u $\quad$ xams Sru? la-əš-šajara

WERE-3PL five branches to-the-tree

(28) a. *kaan tlat Y̌šuš Sind əš-šajara

WAS.3SG three nests at the-tree 
Deconstructing Possession

b. kaan-u tlat Šuuš $\quad$ Sind əš-šajara

WERE-3PL three nests at the-tree

'Three nests were near the tree.'

Humans are no different in this respect. When associated with functional nouns, hence marked by $l a-$, rich agreement is impossible, on a par with (27) (cf. Hoyt 2000):

a. kaan tlat ulaad la-mona

WAS.3SG three kids to-mona

'Mona had three kids.'

b. $\quad$ *kaan-u tlat ulaad la-mona ${ }^{12}$

WERE-3PL three kids to-mona

A related correlation is attested in English (Hornstein et al. 1995). Though Standard

English has agreement with the associate in an existential, in some varieties of English the verb can optionally fail to agree with the post-verbal associate, similar, in a way, to what we find in PA. Here too, the pattern of agreement discriminates the relations, and the Temporary Locative construal requires full agreement. (30a), which lacks agreement with the associate, is similar to PA in allowing only the Part-Whole construal. It can only mean that this room is not equipped with toilets, i.e. it is not a men's room. (30b), with full agreement, has this reading, but can also be interpreted to refer to the toilet storage room, which seems to have been cleared of toilets, i.e. the temporary construal (example taken from Hornstein et al. 1995).

\footnotetext{
${ }^{12}$ To the extent that plural agreement is possible, it depends on the addition of members to the list, in (i), suggesting that the conjunction triggers rich agreement, and supporting the basic observation that Part-Whole is incompatible with rich agreement.

i. kaanu tlat ulaad la-mona, xams ulaad la-samira...

WERE.3PL three kids to-Mona, five kids to-Samira...

'There were Mona's three kids, Samira's five kids,...'
} 
(30) a. There appears to be no toilets in this room

b. There appear to be no toilets in this room

Cross-linguistically, then, the pattern of agreement distinguishes the relations, supporting our claim that choice of preposition in PA correlates with a syntactic difference. In both languages, the indefinite on the Locative construal requires full agreement and the indefinite on the PartWhole construal can go without agreement. As an independent argument DP, the indefinite on the Locative construal must check Case. Following standard assumptions, Case checking by DP goes hand in hand with agreement on the verb, whether achieved by full DP movement to SpecTP, or, in the case of existentials, by feature movement (Chomsky 1995) or Agree (Chomsky 2000). While the familiar licensing requirement on independent argument DP neatly accounts for English locatives, we have reason to suspect that a full account of PA (28) is somewhat more complex. For one thing, with lexical unaccusative $\mathrm{V}^{\mathrm{o}}$ we observe free variation between rich and poor agreement, suggesting that independent argument DP in PA, unlike English, does not in general require full agreement. If not, the requirement for full agreement cannot be made to follow simply from the requirements imposed by DP, and will also implicate the properties of the copula, examined in detail in sections $4-6 .{ }^{13}$ For present purposes, and without assuming that the workings of phi-features and full DP licensing are identical across English and PA, it is sufficient that the requirement for rich agreement in PA patterns with the option to occur in pre-copular position. We argue shortly below that rich agreement in PA

\footnotetext{
${ }^{13}$ The question we leave open here is what exactly excludes poor agreement on the Locative construal. We come back to this in section 6 after examining a broader class of relevant copular configurations and laying out our analysis of the obligatory copula as the realization of domain extending head movement to $\mathrm{I}^{\circ}$. Coupled with our claim, developed in the context of (35) below, that the sole requirement imposed by poor agreement is EPP checking, that EPP is regulated only at PF, and that PF movement is subject to Procrastinate, we derive the fact that movement of DP to SpecIP with poor agreement is incompatible with the copula because it must take place at PF, beyond the point in the derivation at which the realization of the copula is motivated. See Section $6 \mathrm{fn} .27$ for more discussion.
} 
always has DP in specIP. The indefinite in Part-Whole, in contrast, cannot raise to spec IP; accordingly, it cannot occur with rich agreement.

The distribution of interpretations across agreement patterns is not, however, fully identical. In PA, Part-Whole is incompatible with agreement, while the English existential construction on this construal does allow agreement, as in (30b). The claim that the indefinite is represented as a functional $\mathrm{N}^{\circ}$ explains the lack of agreement in PA. As a functional noun, the indefinite is a sub-part of DP which is not, itself, a constituent. As such, it isn't an appropriate goal in the sense of Chomsky (2000), and agreement is impossible. In PA, then, we observe a full correlation between categories which can raise and categories which require rich agreement. Both phenomena are restricted to the indefinite subjects of locatives. The indefinite in the PartWhole construal, in contrast, cannot raise and cannot exhibit rich agreement. In English, in contrast, the indefinite in the Part-Whole construal cannot raise (recall (5)-(8) in section 2) though it can exhibit full agreement.

We take the combination of English-internal facts and the contrast with PA to favor the model of Chomsky (1995) over Chomsky (2000). While agreement in Chomsky (2000) proceeds uniformly in terms of Agree, the agreement model of Chomksy (1995) has agreement in existentials implemented as covert feature movement, and agreement with preverbal subjects as overt movement of the full DP. The difference between English and PA with respect to agreement on the Part-Whole construal can be captured only in terms of Chomsky (1995). We can state the difference as follows: In English, the Part-Whole indefinite allows covert feature 
movement even though the indefinite cannot raise. In PA, in contrast, there is no option for covert feature movement, hence Part-Whole cannot exhibit rich agreement. ${ }^{14}$

The cross-linguistic difference in the availability of covert feature movement with PartWhole is independently supported by a systematic cross-linguistic difference in the relation between agreement and scope. Unlike English, rich agreement in PA has interpretive consequences. With rich agreement, the scope of the agreeing DP is fixed at a unique position, which we take to be SpecIP. This implies two differences, compared to English. Whereas in English, full agreement is compatible with a DP located lower than SpecIP (associated with covert feature movement), and also with DP scoping below its surface position (reconstruction), PA rich agreement fixes scope at SpecIP. A DP in SpecIP with rich agreement cannot be interpreted lower than its surface position, i.e. it doesn't reconstruct. Conversely, when DP is lower than SpecIP, there is no rich agreement. ${ }^{15}$ The incompatibility of a Part-Whole indefinite with rich agreement follows, then, from the general alignment of agreement and scope, given the unavailability of raising to SpecIP.

The general alignment of agreement and scope is clearly observed with the class of unaccusative verbs which allow poor agreement. (31) shows that poor agreement is necessarily associated with narrow scope, whereas rich agreement introduces the option for wide scope.

\footnotetext{
${ }^{14}$ An important issue raised by this way of stating things concerns the scope of parametric difference and whether these differences could conceivably be assigned to LF such that English has covert feature checking and PA lacks it (Marcel Den Dikken, p.c.). We agree about this shortcoming of our account as it presently stands and hope to integrate it, in future work, into a general theory of the interpretive effects of phi-features. Note, in this respect, that on our present formulation the absence of covert feature movement and the absence of reconstruction with rich agreement (see immediately below) are treated as separate properties, essentially in the spirit of Sauerland \& Elbourne (2002). As a first step, well beyond the scope of this study, we would need to understand whether the two properties necessarily go hand in hand or whether their co-occcurence in British English and PA is merely accidental. On the former scenario, agreement systems will differ such that in some languages agreement fixes scope, generally, not in the more specific detail related to covert feature movement.

${ }^{15}$ See Den Dikken (2001) and especially Sauerland \& Elbourne (2002) for virtually identical facts with the special plural agreement found in some varieties of British English with singular group denoting nouns like team, committee, etc.
} 
With a fronted quantificational adverb, the subject can scope over it only if associated with rich agreement:

\begin{tabular}{|c|c|c|c|c|c|}
\hline \multirow{2}{*}{ a. } & kull yom & biji & ulaad & Sa-S-Saff & $\forall>\exists ; * \exists>\forall$ \\
\hline & every day & come.3sG & children & to-the-class & \\
\hline \multirow{3}{*}{ b. } & \multicolumn{5}{|c|}{ 'Every day kids come to class.' } \\
\hline & kull yom & bij-u & ulaad & Sa-S-Saff & $\forall>\exists ; \exists>\forall$ \\
\hline & every day & come-3PL & children & to-the-class & \\
\hline
\end{tabular}

'Every day kids come to class.'

We take this to mean that rich agreement fixes the interpretive position of DP at SpecIP. The ambiguity of (31b), and in particular the reading in which the subject scopes under the quantificational adverb, follows from the surface position of the quantificational adverb above the subject in SpecIP. The reading where the subject scopes above the adverb reduces to reconstruction of the adverb. Crucially, then, narrow scope of the subject in (31b) is not the result of subject reconstruction to a $v \mathrm{P}$-internal position. This is supported by the relative scope of subjects and objects in simple transitive clauses. A simple transitive such as (32) has only one reading, in which the subject scopes over the object. For the object to scope over the subject, the object must raise beyond the surface position of the subject in SpecIP, as in (32b). Taking scope ambiguity in English to result from short object QR coupled with subject reconstruction to (roughly) SpecvP (Hornstein 1994, Johnson \& Tomioka 1997, Fox 2000), and assuming that object QR in PA is no different from English, the absence of ambiguity in (32a) follows from the absence of subject reconstruction. 
Deconstructing Possession
a. tlat banaat
baas-u
kull walad
$\exists>\forall ; * \forall>\exists$
three girls kissed-3PL every boy
'Three girls kissed every boy.'
b. kul walad tlat banaat baas-u-hu $\exists>\forall ; \forall>\exists$
every boy three girls kissed-3PL-him
'Every boy, three girls kissed him.'

The interpretive pattern in (32) is determined by rich agreement, not word order. A postverbal subject shows the same scope pattern as long as it is associated with rich agreement. In VS order as well, ambiguity arises only with overt object fronting:
a. baas-u
tlat banaat
kull walad
$\exists>\forall ; * \forall>\exists$
kissed-3PL three girls every boy
'Three girls kissed every boy.'
b. kull walad baas-u-hu that banat $\quad \exists>\forall ; \forall>\exists$
every boy kissed.PL-him three girl
'Every boy, three girls kissed him.'

Agreement in PA is thus markedly different from agreement in English, correlating as it does with scope. This accounts for the agreement difference with respect to Part-Whole. (31)(33) show that poor agreement correlates with obligatory narrow scope for the indefinite, forming the basis of our cross-linguistic generalization: in both English and PA the indefinite in the Part-Whole construal is obligatorily interpreted with narrow scope. In English, where full agreement is also allowed, the indefinite is nevertheless confined to the existential construction. This is possible because full agreement in English does not determine scope in the way that it does in PA. 
The restriction of poor agreement to obligatory narrow scope persists in the copular constructions examined above. While the poorly agreeing indefinite in (34a) scopes only below a fronted quantificational adverb, rich agreement opens up the possibility for wide scope of the indefinite, in (34b), which we have taken to be due to reconstruction of the quantificational adverb:

a. hanni, kull yom kaan Sind-o xams ulaad $\forall>5 ; * 5>\forall$

Hanni, every day WAS.3SG at-3SG.M five kids

'Hanni has every day five kids.'

b. hanni, kull yom kaan-u find-o xams ulaad $\forall>5 ; 5>\forall$

Hanni, every day WERE-3PL at-3SG.M five kids

'Hanni has every day five kids.'

Summarizing so far, we have shown that the similarity and difference between English and PA follow from the syntactic distinction between the Locative construal and Part-Whole, combined with the general cross-linguistic difference in the relation of agreement and scope. The two languages are identical in confining the indefinite to obligatory narrow scope. Rich agreement with the associate is possible in English due to the availability of covert feature checking, a mechanism absent in PA, where rich agreement fixes scope at SpecIP.

To complete the picture, we briefly sketch an analysis of scope fixing by rich agreement. PA exhibits a correlation between agreement, scope, and position, to recall: for the unaccusative verbs which show the distinction, preverbal subjects are necessarily associated with rich agreement, whereas post-verbal subjects are compatible with rich agreement and poor agreement. We have also seen that scope correlates with agreement, not position. The situation 
recalls, to some extent, the distribution of DP types and interpretations across positions in Italian discussed by Longobardi (2000), where among the two possible types of post-verbal subjects, one is identical to a preverbal subject. In the spirit of Longobardi (2000), we assume, accordingly, that the agreeing subject in SV and in VS is in the same position, and that the difference follows from the extent of V-movement: less V-movement produces SV; more Vmovement produces VS. Assuming some version of the mapping hypothesis (Diesing 1992), a DP subject associated with rich agreement is interpreted in the area of SpecIP, whereas a DPsubject associated with poor agreement is interpreted within $v \mathrm{P}$, possibly bound by existential closure. We will not assume, however, that DP in the poor agreement paradigm is necessarily located, in the syntax, within $v \mathrm{P}$. The results of the sections ahead strongly suggest that the null expletive strategy is not available in PA. It follows, therefore, that in the poor agreement paradigm as well, DP must leave $v \mathrm{P}$ to check EPP. At the same time, the subject is confined to post-verbal position. To reconcile EPP checking with the obligatory post-verbal position of the subject in poor agreement, we adopt an articulated IP (Henry 1995; Jonas \& Bobalijk 1996; Cardinaletti \& Roberts 2000): rich agreement is associated with the higher projection, and EPP checking is associated with the lower position. These positions are designated as AgrP and TP in the derivations in $(35):{ }^{16}$

\footnotetext{
${ }^{16}$ See also Henry \& Cottell (2007). We remain agnostic regarding the position of $\mathrm{V}^{\mathrm{o}}$ in (35b), since it is sufficient that either one of the possibilities in (35a) produces VS with the subject in spec TP. We include the AgrP layer in (35b) only for expository purposes, and assume, in what follows that, in the spirit of Bobalijk \& Thrainsson (1998), AgrP is present only when rich agreement is also present.
} 
a. Rich agreement

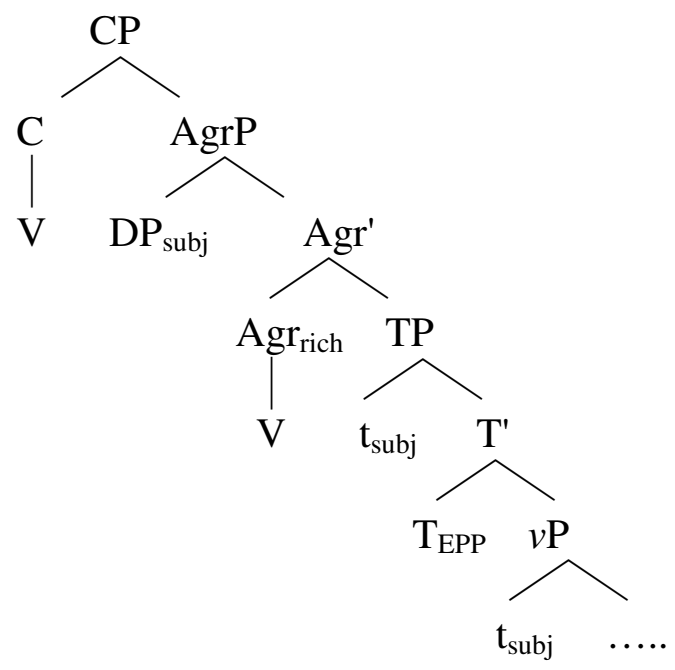

b. Poor agreement

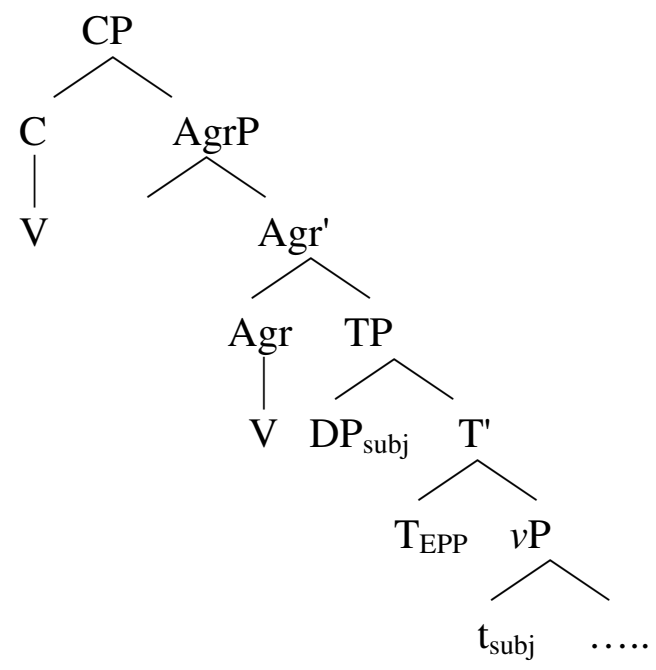

Given the syntax in (35), where in both trees the subject is external to $v \mathrm{P}$, we are left with the scope contrast: DP in (35a) cannot reconstruct whereas DP in (35b) must reconstruct. The split between impossible reconstruction and obligatory reconstruction meshes perfectly with the analysis of Total Reconstruction proposed in Sauerland \& Elbourne (2002). On that analysis of A-chain reconstruction, distinct operations produce reconstructed and non-reconstructed readings: Total Reconstruction is a product of $\mathrm{A}$-movement at $\mathrm{PF}$, and only stem movement can feed LF. Following Sauerland \& Elbourne (2002), A-movement in (35a) is stem movement, whereas A-movement in (35b) is PF movement, with DP necessarily interpreted within $v \mathrm{P}$. The division into stem movement in (35a) and PF movement in (35b) should not be surprising given the additional rich agreement trigger in (35a). More specifically, rich agreement must be interpreted at LF, the level at which relative scope is interpreted, while EPP checking is regulated only at PF (Landau 2007). Total Reconstruction as PF movement in (35b) means that EPP must be able to be checked as late as PF. But if A-movement in (35a) is to be represented also at LF, it must take place in the stem, before the split into LF and PF. We can say, then, in 
the terms of Chomsky (1995) that rich agreement is strong, forcing movement in the overt component, where what we mean, concretely, is that its effects must be visible at LF, the level at which scope position is interpreted. The EPP, as such, regulates only PF. The idea that the EPP is ultimately regulated at PF is compatible with the possibility that movement to SpecTP for the purposes of EPP checking may also take place in the stem. In some cases it must, if it is also to feed LF. In (35a), direct movement to SpecAgrP, skipping TP, would bleed the possibility for EPP checking by DP at PF. ${ }^{17}$ The fact that poor agreement necessarily yields narrow scope and reconstruction, hence on our account, is delayed to $\mathrm{PF}$, allows us to make the stronger claim that EPP at PF is governed by Procrastinate. Delaying EPP checking movement to PF is preferred, everything else being equal; EPP checking in the stem is possible only if delaying it to PF would lead to a violation of the sort suggested for (35a). On the account we have developed, the sole requirement imposed by poor agreement is EPP checking. Since EPP checking is typically delayed to PF, and PF movement entails total reconstruction, a poorly agreeing DP is always interpreted with narrow scope.

\section{Towards the deconstruction of possession}

We have seen in the previous sections that locative DP-PP requires raising of the indefinite or agreement, repeated in (36).
a. $\quad$ kaan

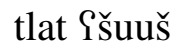
Find
əš-šajara

WAS.3SG three nests at the-tree

\footnotetext{
${ }^{17}$ Thanks to Marcel Den Dikken (p.c.) for sharpening the point.
} 
Deconstructing Possession

b. kaanu tlat ఢ̌uuš ind əš-šajara

WERE.3PL three nests at the-three

'Three nests were near the tree.'

Here we show that agreement is not necessary. While (36a) is ungrammatical, other operations, such as inversion of the PP or insertion of a locative expletive conspire to allow the Locative construal in the poor agreement configuration.

Our study of the poor agreement paradigm allows us to trace a number of ingredients which ultimately also figure in the derivation of English HAVE. In the course of our analysis we encounter a variety of PP-fronting operations which are more clearly discernable in PA than in English because here too overt marking tracks underlying structure. The idea that PP-fronting is to be related, at some level, to HAVE constructions, is present already in Freeze (1992). However, as we continue to show below, the division between locative PPs and Whole PPs is crucial for the analysis of PP-fronting, and by extension a finer understanding of HAVE.

\section{The derivation of existentials: EPP checking with poor agreement}

In this section we will consider differences between Predicate Locatives and Part-Whole constructions with respect to EPP checking when $\mathrm{I}^{\mathrm{O}}$ is specified for poor agreement. We have seen that the Locative construal is impossible in the order DP-PP in the absence of agreement, though Part-Whole is fine, both with human and non-human locations in (37 \& $\left.37^{\prime}\right)$.

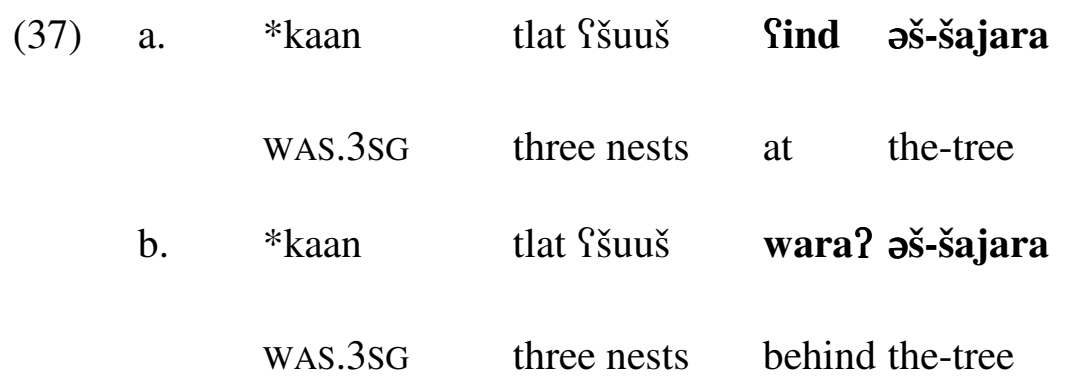


Deconstructing Possession
c. kaan
tlat Sru?
la-əš-šajara

WAS.3SG three branches to-the-tree

'The tree has three branches.'

$\left(37^{\prime}\right)$
a. *kaan
tlat ulaad
find mona
WAS.3SG
three kids
at Mona
b. *kaan
tlat ulaad
wara? mona
WAS.3SG
three kids
behind mona
c. kaan
Pijreen Tuwal la-saami
WAS.SG
legs long to-Sami
'Sami had long legs.'

We now present two major strategies for salvaging the Locative construal with poor agreement: PP Inversion to the right of copular kaan, in (38a/38'a), or insertion of an expletive, fiih $^{18}$, in (38b/38'b). Both strategies are compatible with Part-Whole, as (39) illustrates. In other words, what is obligatory on the Locative construal in the poor agreement paradigm, is optional for PartWhole:
a. kaan
Sind / wara? əš-šajara
tlat $\Upsilon$ šuuš
WAS.3SG
at / behind the-tree
three nests
'Three nests were near / behind the tree.'

\footnotetext{
${ }^{18}$ In what follows, we develop an analysis of fiih as a locative expletive (Mohammad 1998). The distribution fiih is quite widespread even within the domain of non-verbal sentences. Here we limit ourselves to the construals under discussion.
} 
Deconstructing Possession

b. kaan fiih tlat Y̌uuš ind / wara? əš-šajara

WAS.3SG FIIH three nests at / behind the-tree

'There were three nests near / behind the tree.'

(38') a. kaan Sind / wara? mona tlat ulaad

WAS.3SG at / behind Mona three kids

'Three kids were at Mona's / behind Mona.'

b. kaan fiih tlat ulaad Sind / wara? mona

WAS.3SG FIIH three kids at / behind Mona

'There were three kids at Mona's / behind Mona.'

(39)

a. kaan la-əš-šajara tlat Sru?

WAS.SG to-the-tree three branches

b. kaan fiih tlat Sru? la-əš-šajara

WAS.3SG FIIH three branches to-the-tree

вотн: 'The tree had three branches.'

(39') a. kaan la-saami Pijreen Tuwal

WAS.SG to-Sami legs long

b. kaan fiih Pijreen Tuwal la-saami

WAS.3SG FIIH legs long to-Sami

вотн: 'Sami had long legs.' 


\subsection{Locative existentials}

Poor agreement is syntactically different from rich agreement. The sole requirement it imposes is EPP checking, and this can be done by a variety of categories since no nominal features are involved (Collins 1997; Holmberg 2000; Bailyn 2004; Biberauer \& Roberts 2008, among others). We will consider each strategy in turn and argue that both PP Inversion and fiih insertion are strategies to check EPP. The EPP syntax we develop further supports our basic claim that Part-Whole is contained within a DP, from which we argue that the non-obligatory nature of these operations follows.

PP Inversion and fiih insertion necessarily derive existentials. Rich agreement in these contexts is impossible:
a. $\quad ?$ kaan-u
Sind / wara? əš-šajara
tlat Y̌uuš

WERE.3PL

at / behind the-tree

three nests

b. *kaan-u

fiih tlat $\check{\text { šuuš }}$

Sind / wara? əš-šajara

WERE.3PL FIIH three nests at / behind the-tree

(40’) a. ?? kaan-u Sind / wara? mona tlat ulaad

WERE.3PL at / behind Mona three kids

b. *kaan-u fiih tlat ulaad Sind / wara? mona

WERE.3PL FIIH three kids at / behind Mona

Given the relation between agreement and scope, the ungrammaticality of rich agreement means that the locatives in (38) are true existentials in the specific sense that the indefinite is limited to narrow scope ( Kuno 1971). When agreement is rich, SpecIP must be filled by a full argument DP. In the absence of rich agreement and a full DP in SpecIP, the sole formal requirement is EPP 
checking, and this can be done by a category lacking phi-features, either PP or expletive fiih (for the similarity of English There-insertion and Locative Inversion see Hoekstra \& Mulder 1990;

Freeze 1992; Moro 1997). While there is certainly a choice between EPP satisfaction by PP Inversion or by fiih insertion, one or the other is obligatory; the result is that the DP remains below SpecIP and is interpreted with narrow scope. A side benefit of our analysis is that EPP is always satisfied overtly, by either Merge or Move. This implies that insertion of a null expletive for the sole purpose of EPP checking is not available in PA.

\subsection{Part-Whole existentials ${ }^{19}$}

Assuming, as seems natural, that the EPP applies identically in Locatives and in Part-Whole, PP Inversion and fiih insertion in Part-Whole in (39) are identical to the Locatives in (38). In both cases inversion is PP-movement to SpecIP and the past tensed copula kaan is in $\mathrm{C}^{\mathrm{o}}$ (to be motivated in more detail in section 6). The question which immediately arises, then, is why do these operations appear to be optional on the Part-Whole construal, in $\left(37 \mathrm{c} / 37^{\prime} \mathrm{c}\right)$ ? Here too, our proposal that Part-Whole is contained within a DP becomes handy: the containing DP can check EPP. The sections to follow motivate this claim and account for the alternatives observed. In the course of our analysis, we also elaborate on the syntactic operations which derive propositional readings from a DP source.

\subsubsection{PP Inversion}

We begin with the grammaticality of (37c), where neither inversions nor fiih insertion are necessary. We have already given a preliminary reason to suspect that Part-Whole has its origins in a DP structure, based on the distribution of relative clause modification (see section 2).

\footnotetext{
${ }^{19}$ For reasons of space only the examples presenting relations between inanimate are given, but the judgments and analysis apply equally to animates.
} 
Further motivation for a containing DP can be seen in (41), where the DP is interpreted as a full argument, with $l a$-DP inside it, and agreeing with the overt copula.

(41) kanaat [DP bint la-ra?is]

WAS.3F.SG daughter to-the president

'The president's daughter was there'

Where $l a$-DP is uncontroversially within the containing DP, there is no propositional relation between la-DP and the head noun; (41) cannot mean The president had a daughter. How then are the propositional interpretations of Part-Whole derived? It appears that an overt copula plays a crucial role. In the present tense, where there is no copula and where the neutral word order is subject-initial, Part-Whole propositional readings are impossible:

a. *tlat Sru? la-ə̌̌-šajara

three branches to-the-tree

b. tlat ९̌suuš $\quad$ ind əš-šajara

three nest at the-tree

'Three nests are near the tree.'

Following Doron (1983), Rapoport (1987), and Déchaine (1993), we assume that non-verbal predications like (42) do not include a null verbal copula. This still leaves open the possibility that in PA, with its rich/poor agreement distinction, constructions like (42) are ambiguous between having null rich agreement and null poor agreement. A null rich agreement analysis explains the contrast in (42), since only on the Locative construal can the indefinite surface with overt rich agreement. (42a) is out, therefore, for the same reason as (27b), (29b) in section 3. This leaves us with the ungrammaticality of (42a) with null poor agreement. With poor agreement, the copula is required, as shown by (37c), repeated below: 

a. kaan
tlat Sru?
la-əš-šajara

WAS.3SG three branches to-the-tree

'The tree had three branches.'

b. kaan

Pijreen Tuwal la-saami

WAS.SG

legs long to-Sami

'Sami had long legs.'

What then is the contribution of kaan in delivering the propositional reading? We suggest that the crucial ingredient for the propositional interpretation is extraction of $l a$-DP from the containing DP. ${ }^{20}$ kaan is only indirectly involved, in allowing the remnant to take an additional step of EPP-satisfying movement. (44) shows that with la-DP external to the containing DP, the interpretation is propositional, and crucially, does not require the aid of the copula. An inverted bare structure without the copula yields a possessive proposition.

la-saami Tijreen Tuwal

to-Sami legs long

'Sami has long legs.'

We return to the fuller details of Bare Inversion below (section 6), but for present purposes, it is sufficient that $l a$-DP in (44) checks EPP in SpecIP, exactly as in the past tense PP Inversion constructions discussed above. Assuming that $l a$-DP has necessarily extracted from the

\footnotetext{
${ }^{20}$ Our focus must be limited to the consequences of this assumption and we set aside the finer details having to do with its motivation. Very roughly, the significant difference between a propositional interpretation, with PP as main predicate, and the interpretation with PP internal to DP which we have in mind has to do with the scope of the determiner. The determiner in the propositional configuration does not seem to scope over the possessee. 'Three' in (ib) does not entail that Mary has exactly three files (see Szabolsci 1994 for some discussion):

(i) a. Mary has exactly three files

b. $\quad$ The police opened three of Mary's files

For present purposes, it is sufficient that extraction of $l a$-DP from the containing DP removes it from the scope of the determiner. On the view of Total Reconstruction adopted in section 3, combined with the necessarily stem-status of $l a$-DP extraction motivated here and below, it follows that $l a$-DP does not reconstruct back into DP.
} 
containing DP, the remnant DP [DP three branches $t_{2}$ ] checks EPP in SpecIP in (31). An additional landing site for the extracted $l a$-DP is provided by FP. The derivations of (44) and (43) are given in (45a) and (45b), respectively:

a. Bare Inversion

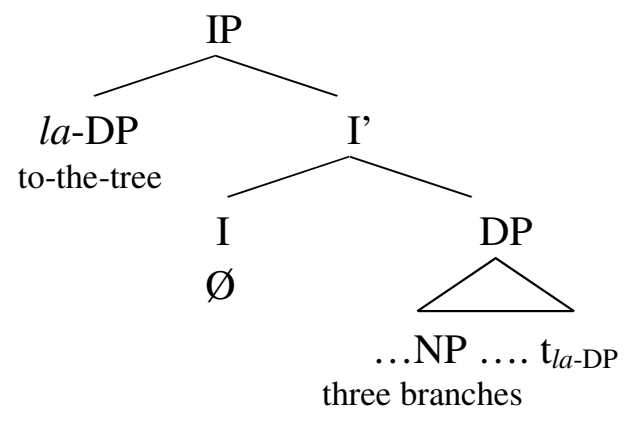

b. Double Inversion

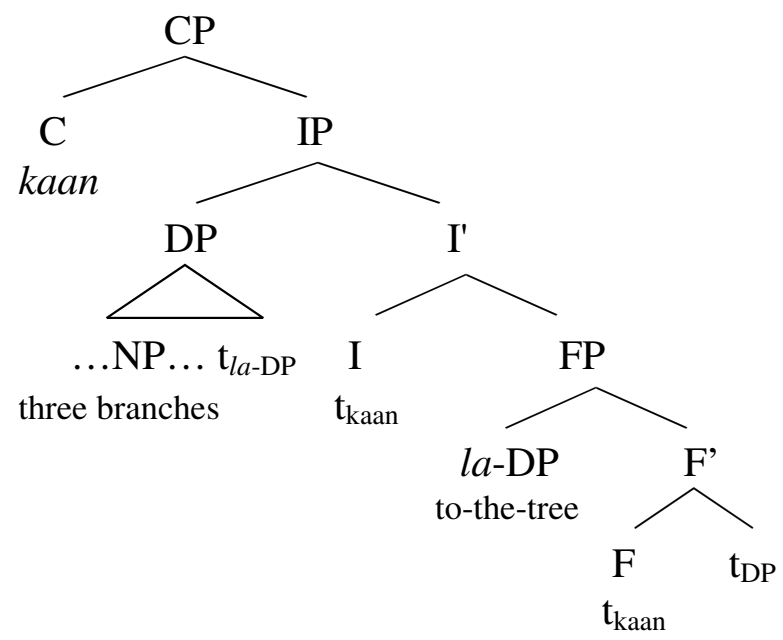

Continuing to assume that there is no null copula in (45a), the containing DP is the immediate sister of I and hence, the immediate position above it is the EPP position. Therefore, the extracted $l a$-DP necessarily moves into this position and further fronting of the indefinite is impossible (44a). EPP checking and la-DP extraction are dissociated in (45b), facilitated by the introduction of kaan. Two additional ingredients are at stake: the introduction of additional structure, FP, as a landing site for the extracted la-DP; and the possibility for the remnant DP to cross $l a$-DP on its way to SpecIP, constrained by Relativized Minimality. We will have much more to say about the circumvention of Relativized Minimality by the realization of the copula in section 6. For present purposes, it is sufficient that the introduction of the copula facilitates the disassociation of EPP checking and la-DP extraction either by introducing additional structure 
(in the sense of Moro 1997), or by allowing the remnant DP to cross la-DP in FP (as a Linker, in the sense of Den Dikken 2006). The upshot is that, appearances aside, (45b) is a case of Double Inversion.

Summarizing so far, we have argued that PP-fronting to the right of kaan satisfies the EPP, and is therefore obligatory on the Locative construal. What appears to be absence of inversion with Part-Whole turns out to be better understood in terms of Double Inversion. Our Double Inversion analysis capitalizes, syntactically, on the presence of a containing DP (in service of EPP checking), and in this respect explains the apparent optionality of PP Inversion. Yet given the syntax of the containing DP, it also accounts for the availability of a propositional interpretation, consistent with the grammaticality of Bare Inversion and the ungrammaticality of canonical non-verbal sentences.

\subsection{2 fiih insertion}

We turn now to the second strategy, the insertion of expletive fiih, in (38b) and (39b), repeated below:

a. kaan fiih tlat @̌̌uuš Sind / wara? əš-šajara

WAS.3SG FIIH three nests at / behind the-tree

'There were three nests near / behind the tree.'

b. kaan fiih tlat Sru? la-əš-šajara

WAS.3SG FIIH three branches to-the-tree

вOTH: 'The tree had three branches.'

Once again, this strategy is obligatory for Locatives and optional for Part-Whole. The obligatory nature of fiih insertion in the absence of PP-fronting is another consequence of the need to check 
EPP. For concreteness, we assume that fiih is merged in SpecIP, and the need for PP-fronting is neutralized. Since the only formal requirement imposed by poor agreement is EPP checking, the indefinite is free to remain low, where it is interpreted with obligatory narrow scope. This delivers the existential nature of the construction.

Our analysis of (37c) in terms of Double Inversion involving la-DP extraction followed by fronting of the remnant DP to SpecIP in the service of the EPP directly explains why fiih can fail to occur in the Part-Whole construal. The more challenging question, from our perspective, is what allows fiih to be merged in (39b) at all. Given the analysis outlined here, the problem with (39b) is the following: the positioning of fiih in SpecIP entails that the remnant DP has not been fronted. Given the word order, this can only mean that la-DP extraction has not occurred. How then is the propositional reading derived? To answer this question, we assume that $l a-$ extraction, when not in the service of EPP checking, can be delayed to LF, the level at which propositional structure must be represented. Since EPP checking is established by fiih, laextraction, as a requirement on Full Interpretation may be delayed to LF. For concreteness, we assume an LF process akin to Expletive Replacement (Chomsky 1986), but nothing crucial hinges on this. The structural representations of (46a-b) are given in (47). ${ }^{21}$

\footnotetext{
${ }^{21}$ For expository purposes we continue to assume an FP and a simple bare SC structure, to be further refined in section 6 .
} 
a. kaan fiih $\mathrm{DP} \mathrm{PP}_{\mathrm{Loc}}$

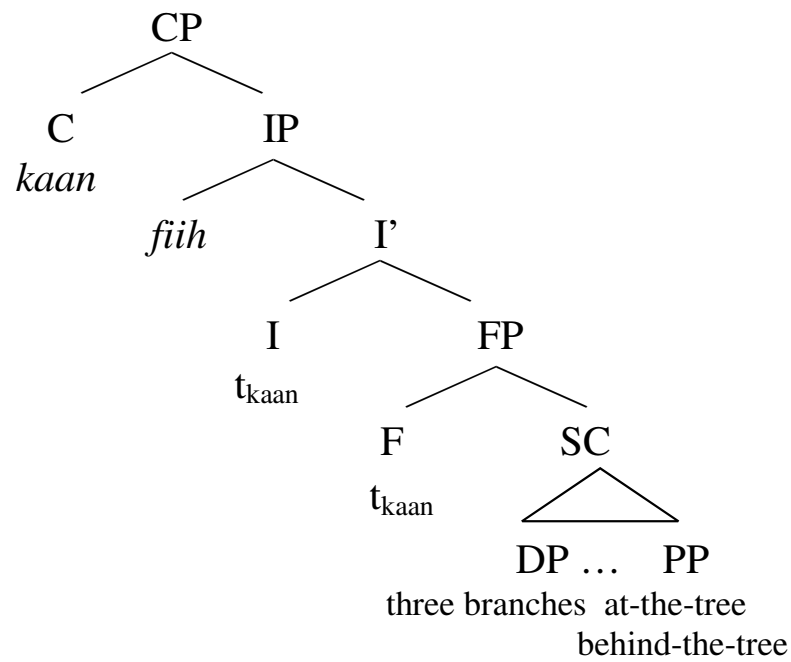

b. kaan fiih DP la-DP

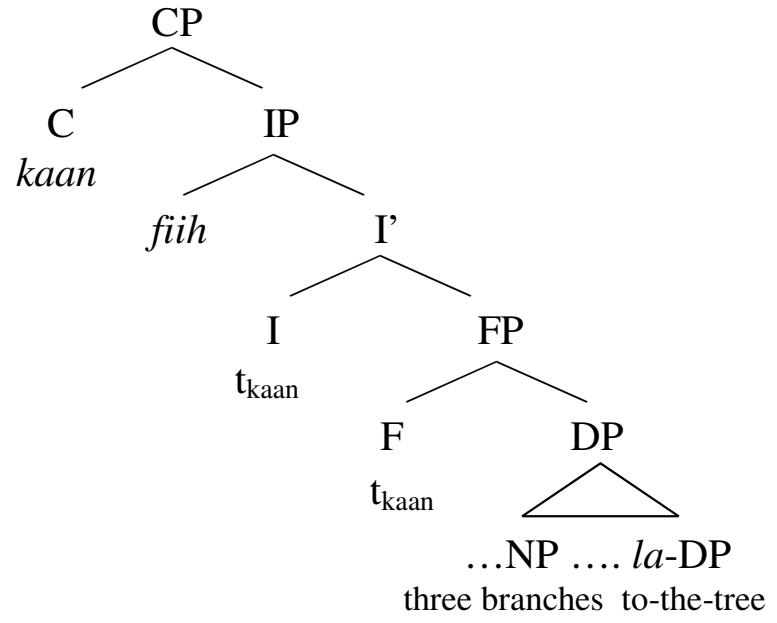

Independent support for the analysis of (46b), according to which the syntactic derivation of clausal interpretation can be delayed to LF is provided in (48). (48a) shows that a propositional interpretation is available when fiih precedes DP-PP. Without fiih, to recall, a clausal interpretation is unavailable in the absence of kaan:

a. fiih tlat Sru? la-ə̌̌-šajara

FIIH three branches to-the-tree

'The tree has three branches.'

b. $\quad$ ta-əš-šajajara

three branches to-the tree

c. kaan tlat Sru? la-əš-šajara

WAS.3SG.M three branches to-the-tree

'The tree had three branches.' 
(48) shows that the structure provided by kaan is not an absolute requirement, given fiih. We have assumed that $l a$-DP extraction is necessary for interpretation, and have argued that with kaan the operation is overt. Given the word order in (48), la-extraction must be covert, made possible due to EPP checking by fiih. This is schematized in (49):

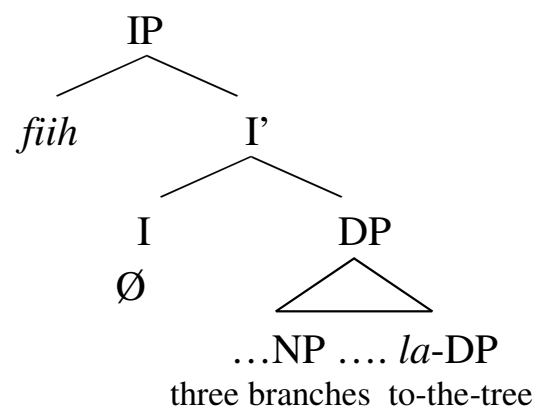

\subsection{Summary}

Summarizing, we have shown that fiih insertion and PP Inversion produce existential constructions, with the DP confined to a low position. The existential construction in PA is distinguished by the poor agreement paradigm, which imposes the single requirement that EPP be checked, by fiih, by PP or by a remnant DP.

As we have shown, the robust syntactic differences between Part-Whole and Locative construals persist in the poor agreement paradigm as well, supporting our basic claim that only Part-Whole has a DP-internal source. In the next sections, we broaden this typology and end up claiming that in fact, what is traditionally called 'inalienable possession' also has an applicative source, in addition to the DP-source discussed at length. Here too, the motivation for our claim is purely syntactic and derives from the special restrictions found in Bare Inversion structures discussed below. The Bare Inversion construction reveals the dual nature of Sind-DP, and 
highlights those aspects of PA existentials which are closer to 'possessive' HAVE. The study of these aspects in a HAVE-less language should uncover some of the basic universal mechanisms.

\section{Bare Inversion and Sind on its Part-Whole guise}

Remaining within the poor agreement domain, we now shift the focus from asymmetries between Sind-and la-PPs to structures in which they pattern together and contrast with what we termed in section 2 pure locative PPs. This move will reveal the dual nature of Sind-PP.

Copula-less clauses in the present tense feature a contrast between pure locative PPs and Sind / la- PPs. In a PP-DP order, the former are ungrammatical, while the latter are good (discussed also in Mohammad 1998, 2000; see Cowell 1964 for similar facts in Syrian Arabic). We will call the bare structure in (51)-(53) Bare Inversion.

a. *wara?əš-šajara $\quad$ šuuš behind the-tree nests

b. *wara? mona tlat ulaad behind Mona three kids

(51) a. ind əš-šajara ร̌uuš at the-tree nests 'Near the tree are nests.'

b. Sind mona tlat ulaad at Mona three kids 'Mona has three kids.' 
Deconstructing Possession

a. la-əš-šajara tlat Sru?

to-the-tree three branches

'The tree had three branches.'

b. la-mona tlat ulaad

to-Mona three kids

'Mona has three kids.'

There is only one more preposition in PA which patterns like Sind and la- PPs in allowing Bare

Inversion:

a. maia mona tlat ulaad

with Mona three kids

'Mona has three kids (with her).'

b. maia mona tlat Plaam

with Mona three pens

'Mona has three pens (on her/with her).'

Similar to Sind, the Locative relation expressed by ma 9 a is highly underspecified, and in addition seems to denote 'short term location'. As we show, the similarity of Sind-DP to la-DP is also shared by ma Sa-DP, which like Sind-DP, does not have a DP-internal source. We argue that the special behavior of Sind / ma Sa DPs follows from an analysis in terms of an applicative structure ApplP (Marantz 1993; Pylkkänen 2008).

The clustering of $l a$-DP, Sind-DP, and ma $9 a$-DP patterns, cross-linguistically, with a similar phenomenon found in 'possessive HAVE' constructions. In contrast to the BE paradigm 
seen up until now, here alienable possession is on the side of inalienable possession. Pure

locatives, on the other hand, require a co-indexed pronoun (54d):

(54) a. The tree has many branches

b. John has a sister in Paris

c. John has a / the car

d. The tree has many nests *(in it)

Building on these similarities, we extend our applicative analysis of PA to the English HAVE paradigm in section 7.

\subsection{Poor agreement}

We begin by arguing that Bare Inversion is based on poor agreement morpho-syntax. We have shown above that locative PP Inversion is incompatible with overt rich agreement (40), since rich agreement would have the DP subject in SpecIP (cf. section 3). This is crucial, given our claim that non-inverted bare structure, which is fine with all locatives, features null rich agreement (see discussion of ex. 42). If so, Bare Inversion, could, in principle, be derived from a rich agreement base. But if Bare Inversion had null rich agreement, the restriction to a subset of PPs would remain mysterious.

Independent support for a null poor agreement base comes from the distribution of bare indefinites. Bare indefinites are impossible in preverbal position, including the bare DP-PP order in (55a-b). In the Bare Inversion construction with Sind, however, bare singulars are fine (55c).

(55d) is of course ungrammatical regardless of the indefinite type.

$$
\begin{aligned}
& \text { a. tlat banaat / *bint fi-d-daar } \\
& \text { three girls / girl in-the-house }
\end{aligned}
$$


Deconstructing Possession

b. tlat banaat / *bint Sind saami

three girls / girl at Sami

c. Sind saami tlat banaat / bint

at Sami three girls girl

'Sami has three girls / a girl.'

d. *fi-d-daar tlat banaat / bint

in-the-house three girls girl

Given our claim that rich agreement always has DP in the same position, SpecIP, while with poor agreement, the DP subject may be lower, the availability of bare singular indefinites in Bare Inversion follows on the poor agreement analysis. Our null poor agreement analysis is also consistent with the fact that Part-Whole la-DP is never associated with rich agreement (cf. section 5.2).

\subsection{The position of PP}

The next question to address is the location of the PP, and more specifically whether it occupies the EPP position which hosts PPs in ex. (38a) above, or the topic position. In English Locative Inversion, as is well known (Hoekstra \& Mulder 1990; Den Dikken \& Næss 1993; Bresnan 1994; Collins 1997; Rizzi \& Shlonsky 2006, among others), the fronted PP shows mixed properties, which has implied for some that the fronted PP reaches its final A-bar topic position after touching down in SpecIP. Bare Inversion in PA, as we now show, targets SpecIP, where PP checks the EPP, but there is no further movement to a topic position. ${ }^{22}$ Topicalization in PA is clearly distinguishable from Bare Inversion because it obligatorily hosts fiih. It also allows all locative PPs.

\footnotetext{
${ }^{22}$ On a par with copula inversion in English, where the fronted predicate remains in SpecIP. See Den Dikken (2006) for recent discussion.
} 
In the past tense, where the copula is overt, PP can occur to its left. Agreement on the copula is poor, and any PP will do:
a. $\quad$ ind əš-šajara kaan
fiih tlat ९šuuš
at the-tree WAS.3SG
FIIH three nests
'Near the tree there were three nests.'
b. Sala mona kaan fiih šaršaf
on Mona WAS.3SG $\quad$ FIIH $\quad$ blanket
'On Mona there is a blanket.'

Crucially, fiih is obligatory. This is seen in the past tense example in (57), and again, in the present tense (58), where there is no copula:
a. *Sind əš-šajara
kaan
tlat @̌̌uuš
at the-tree
WAS.3SG
three nests
b. * Fala mona kaan
šaršaf
on Mona WAS.3SG
blanket
a. wara? วš-šajara
*(fiih) Gšuuš
behind the-tree
FIIH nests
'Near the tree (there) are nests.'
b. wara? mona *(fiih) tlat ulaad
behind Mona FIIH three kids
'Behind Mona (there) are three kids.'

(58) 
Given the EPP checking capacity of fiih, (56), with PP to the left of the copula, must involve PPTopicalization, and similarly in the present tense. Since fiih checks EPP in lieu of a low indefinite, Topicalization must proceed from (59a), schematized in (59b):

a. kaan fiih tlat ९̌suuš find ə̌̌-šajara WAS.3SG FIIH three nests at the-tree 'There were three nests near the tree.'

b. $\quad$ BE fiih [sC DP PP $\left.P_{\text {LOC }}\right]$

Returning to our discussion of Bare Inversion, a Topicalization analysis can be excluded, first, because Topicalization requires fiih. This still leaves open the possibility that in Bare Inversion PP fronts to check EPP, as in the derivation under kaan in (38a) above, and from there moves on to topic position. Given that all locative PPs front to check EPP to the right of the copula, Bare Inversion might very well be 'Bare Topicalization'. But if so, it would appear that only a subset thereof can topicalize from SpecIP without the aid of the copula. As it turns out, however, there are substantial reasons to reject a topicalization analysis of Bare Inversion, having to do with the special semantics associated with the construction.

As shown above, the subset of PPs which occur in Bare Inversion are PPs headed by Sind (=at), $m a S$ (=with), and $l a-(=t o)$. Bare Inversion also features special interpretive properties. When the object of the preposition is human, and the head noun is functional, the relation between PP and DP is necessarily inalienable. This is seen clearly in the following minimal pairs, where the (a) examples are Bare Inversions and the (b) examples give inversions under 
fiih. The former give rise to inalienable possession, and the latter produce temporary readings, even for $l a-\mathrm{DP}:^{23}$

(60) a. maia mona taw?am

with Mona twins

'Mona is pregnant with twins.'

b. fiih maia mona taw?am

FIIH with Mona twins

'Mona has twins in her company.'

(61) a. Sind mona tlat ulaad

at Mona three kids

'Mona has three kids.'

b. fiih Sind mona tlat ulaad

FIIH at mona three kids

'Three kids are at Mona's.'

(62) a. la-mona šåar Tawil

to-mona hair long

'Mona has long hair.'

\footnotetext{
${ }^{23}$ The construction in the (b) examples, unlike Bare Inversion, allows all locative PPs:

(i) fiih wara? mona tlat ulaad

FIIH behind Mona three kids

'Three kids are behind Mona.'

The Temporary readings in the (b) examples are thus of a kind with (i), and we assume that PP-fronting under fiih targets spec FP in (47). In the case of $l a$-DP NP order under fiih,, the interpretative contrast with (62a) suggests that $l a$-DP must have a Small Clause source in (62b). See section 6.3 for our analysis of PP-inversion.
} 
Deconstructing Possession

$\begin{array}{lll}\text { b. fiih la-mona } & \text { šåar Tawil } \\ \text { FIIH } & \text { to-mona } & \text { hair long }\end{array}$

'There is long hair for Mona.'

(In the context, for example, of hair extensions at the beauty parlor)

While up until now we have focused on the Part-Whole relation associated with la-, here we see that Bare Inversion forces this meaning on PPs headed by Sind and ma $S$ as well, but only with humans and only when the head noun happens to be functional or relational. ${ }^{24}$ Crucially, no such restriction is observed in (60b), (61b), and (62b), or, for that matter, with the topicalizations above. It follows that Bare Inversion is not topicalization. ${ }^{25}$

\subsection{The Applicative Syntax of Bare Inversion}

\subsubsection{Domain Extension}

Sticking to an analysis in which PP fronts to SpecIP, and agreement is poor, we have an almost minimal pair with inversion to the right of kaan, available to all locative PPs and interpreted as a Temporary Locative:
a.
Sind - ma $9 a-l a-\mathrm{DP}$
NP
Bare Inversion
b. kaan $\mathrm{PP}_{\mathrm{LOC}}$
NP
PP Inversion

The comparison of Bare Inversion and PP Inversion highlights the role of the copula, which up until now we have largely been able to ignore. While it is true that an overt copula is unavailable in the present tense, and so (63a) and (63b) differ primarily in terms of tense, it is also true that $\mathrm{PP}_{\mathrm{LOC}}$ inversion is impossible in the present tense. Therefore, abstracting away from tense, it

\footnotetext{
${ }^{24} \mathrm{cf}$. Dobrovie-Sorin (2005) for a discussion of the semantic difference between the two.

${ }^{25}$ The fact that neither of the structures in which PP is inverted to SpecIP can feed topicalization, i.e. neither Bare Inversion, nor PP Inversion beneath kaan, strongly argues against a (simple) movement approach to the mixed properties of locative inversion. See Lasnik \& Saito (1992) on the unavailability of vacuous topicalization, and Den Dikken (2006) and Rizzi \& Shlonsky (2006) in the context of locative inversion.
} 
appears that the copula is required for movement of pure locatives in (63b) (hence their availability only in the past tense), but not in the Bare Inversions in (63a) (where it is optional, see further below). Continuing to abstract away from tense matters, we refer in what follows to the copula in (63b) as an obligatory copula, and to the copula which may accompany (63a), an optional copula.

The immediate question which arises, then, is why Bare Inversion should be available only to the PPs in (63a), and why it gives rise to the inalienable interpretation observable with humans. As we show below, the answers to these questions are related. The approach we develop proceeds from the assumption that $\mathrm{PP}_{\mathrm{LOC}}$ extraction to SpecIP faces a minimality obstacle, removed by the copula. This is consistent with our earlier claims that copula-less structures do not have a null copula; they are radically nonverbal. From this it follows that Bare Inversion must proceed from a distinct structure.

The positioning of the inverted PP in SpecIP implies A-movement, which in turn means that PP must be able to cross the closer candidate for A-movement, the subject DP. ${ }^{26}$ On any version of relativized minimality (Rizzi 1990) crossing of the subject by PP should incur a minimality violation, everything else being equal. Following Den Dikken (1995), Sichel (1997), and most recently Den Dikken (2006), we assume that PP raising to SpecIP in (51b) is facilitated by parallel domain extending head movement. Den Dikken $(1995,2006)$ argues that this is accomplished by movement of the head of an asymmetrical Small Clause (the head of a Relator Phrase) to the head immediately above it, termed the Linker. Movement of the Relator to the Linker is realized in English as a copula; an obligatory copula signals, therefore, obligatory predicate inversion, accounting for the contrast between (64a) and (64b). (65) shows that the

\footnotetext{
${ }^{26}$ Regarding economy considerations (Collins 1997), we assume that in PA, the derivation with PP fronting is not more costly than the derivation with the subject DP raising to SpecIP, because, crucially, poor agreement does not require an extra step of covert-feature checking. See further below.
} 
presence of the copula is probably not related to 'breaking asymmetry' in the sense of Moro (1990) by adding more structure (from Heycock 1994). The copula is still obligatory even when a specifier, SpecIP, is independently available for the inverted predicate to land in:

(64) a. I consider [John (to be) my best friend]

b. I consider [my best friend *(to be) John]

(65) a. Susan $_{1}$ is considered [ $\mathrm{t}_{1}$ (to be) the best candidate]

b. The best candidate ${ }_{1}$ is considered [ $\mathrm{t}_{1} *$ (to be) Susan]

We propose a similar derivation for $\mathrm{PP}_{\mathrm{LOC}}$ inversion to the right of the copula in (63b).

Following Den Dikken (2006), the Small Clause hosting the predicative PP and its subject is asymmetrical, headed by a RELATOR. The RELATOR head is merely a structural position, which can be realized, in principle, by any category. RP is dominated by FP. Movement of $\operatorname{Rel}^{\mathrm{o}}$ to $\mathrm{F}^{\mathrm{o}}$ allows PP to extract from RP and in doing so, to cross the subject on its way to SpecFP. In the derivation in (66), we take $\mathrm{F}^{\mathrm{o}}$ to be $\mathrm{I}^{\mathrm{o}}$, and PP to land in SpecIP in a single step of movement, the minimal hypothesis. On these structural assumptions, there exists no designated copulaP structure which hosts the copula. An obligatory copula, following Den Dikken (2006), is the realization of domain extending movement, such that movement of $\operatorname{Rel}^{\mathrm{O}}$ to $\mathrm{I}^{\mathrm{o}}$ forces the realization of $\mathrm{I}^{\mathrm{o}}$ as a copula. Subsequent movement of the copula to $\mathrm{C}^{\mathrm{o}}$ produces copula-PPsubject order (strikethrough indicates previous positions in the derivation): 


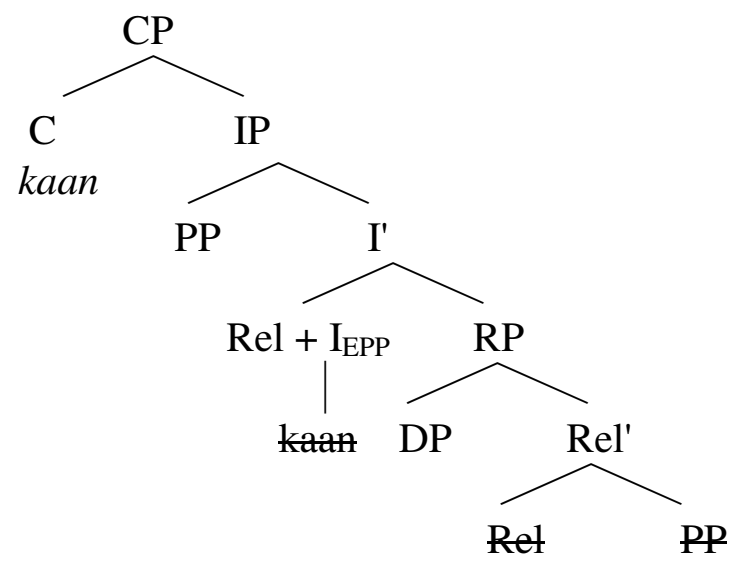

With our analysis of the obligatory copula in place, we turn to fill in the remaining details in the derivation of the obligatory-copula structure encountered in section 5.2.1 above. To recall, the Part-Whole construal requires the copula on the DP-PP order, repeated in (67). Inversion is possible here too, in $(67 \mathrm{c})$ :

a. *?anf Tawil la-saami

nose big to-Sami

b. kaan Tanf Tawil la-saami

WAS.3SG.M nose big to-Sami

'Sami had a big nose.'

c. (kaan) la-saami Panf Tawil

(WAS.3SG.M) to-Sami nose big

'Sami has/had a big nose.'

Since DP-PP predications have null $\mathrm{I}_{\text {rich }},(67 \mathrm{a})$ is ungrammatical on a par with overt rich agreement. Given the DP-internal source of la-DP, the propositional possessive interpretation requires extraction of $l a$-DP from its containing DP. (67b), therefore, must involve two steps of movement: extraction of la-DP to SpecFP, followed by movement of the remnant DP to SpecIP. 
Movement of the remnant DP across the dative in SpecFP is blocked by Relativized Minimality unless $\mathrm{F}^{\mathrm{o}}$ raises to $\mathrm{I}^{\mathrm{o}}$. Domain extending $\mathrm{F}^{\mathrm{o}}$-to- $\mathrm{I}^{\mathrm{o}}$ movement gives rise to the overt realization of the copula, followed by movement to $\mathrm{C}^{\mathrm{o}}$ :

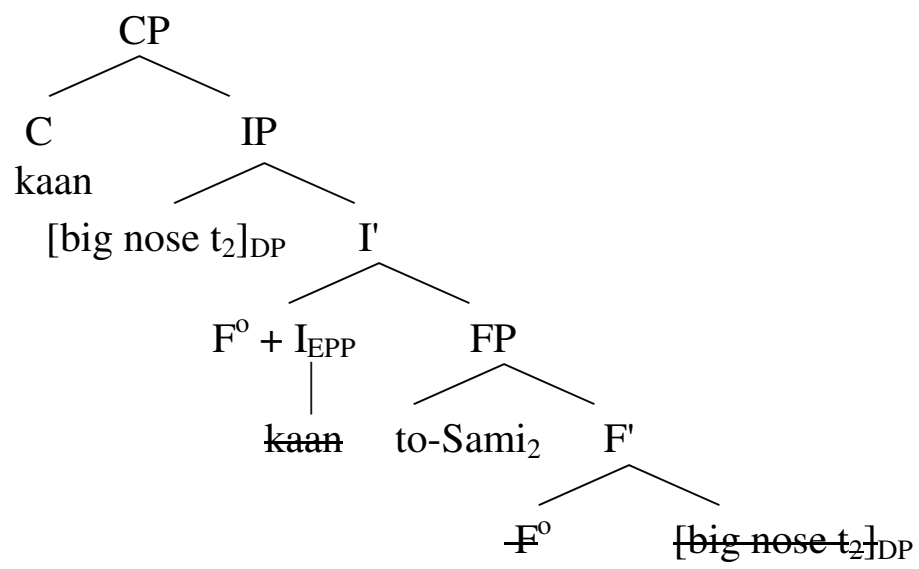

Direct movement of $l a$-DP from SpecFP to SpecIP produces (67c). Since this step of movement does not face a minimality violation, the copula should be optional, and it is. ${ }^{27}$

The analysis of obligatory kaan as domain extending movement to $\mathrm{I}^{\mathrm{o}}$ (by either $\operatorname{Rel}^{\mathrm{o}}$ or some unspecified $\mathrm{F}^{\mathrm{O}}$ ) gives us an immediate explanation for the optionality of the copula in topicalization. Since topicalization directly targets SpecCP, it is an instance of A-bar movement. PP does not compete with the subject and domain extension is unnecessary.

The derivations in (66) and (68), with the copula realizing obligatory head-movement to $\mathrm{I}^{\mathrm{O}}$, entail that no such domain extension is necessary in Bare Inversion. This means that the inverted PP cannot be in the same position as it is in (66), and PP cannot be crossing the subject on its way to SpecIP. The analysis in (68), where extraction of la-DP does not encounter a

\footnotetext{
${ }^{27}$ Another issue to address is the ungrammaticality of the copula with poor agreement and without inversion, kaan DP PP ${ }_{\text {LOC }}$ in (28) Section 3 above. Given that DP can, in principle, check EPP, we left it open why exactly this option is excluded with the copula, but not with a lexical verb (see (35)). Given that EPP checking is regulated at PF and subject to Procrastinate, coupled with the idea that domain extension is necessarily syntactic, $\mathrm{PP}_{\mathrm{LOC}}$ inversion in kaan $\mathrm{PP}_{\mathrm{LOC}} \mathrm{DP}$ will occur in the stem, a motivated violation of Procrastinate. Since no such motivation is available without inversion, DP movement to SpecIP will have to wait until PF, consistent with obligatory narrow scope. This suggests that 'unmotivated' copulas are also syntactic, realized only when SpecIP is also filled in the stem (by inversion or fiih insertion).
} 
minimality problem (the indefinite is a head) cannot be extended to Sind and ma 9 PPs, because these do not have a DP internal source. ${ }^{28}$ The analysis of Sind and ma Sa Bare Inversion will have to proceed, therefore, from a clausal underlying structure, in other words, RP. On our assumptions regarding the role of the obligatory copula, the absence of the copula can only mean that movement from within RP to SpecIP does not encounter a minimality problem. Find and ma 9 a PPs, therefore, must be generated in SpecRP, with DP in complement of Rel ${ }^{\circ}$. From this position, PP is free to raise to SpecIP for EPP checking unaided by domain extension and copula realization $^{29}$ :

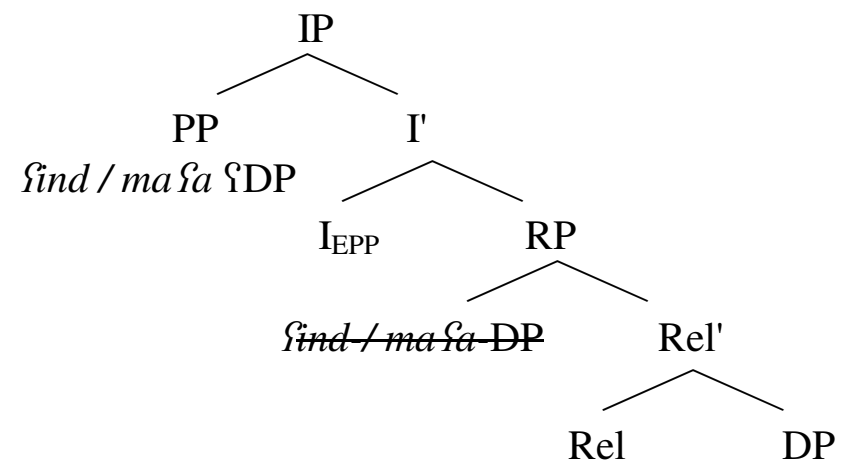

The configuration of RP as in (69) accounts for the syntax of Bare Inversion and makes a direct prediction regarding the interaction of copula realization and interpretation. We expect the copula to be optional here, as it always is when domain extension is unnecessary. We also expect that with human complements to Sind / ma 9 , the structure including the copula should be

${ }^{28}$ As mentioned above, modification by Sind-DP is obligatorily introduced by a relative clause (ex. (21) above). The same is true for ma $9 a$-DP:

$\begin{array}{lrl}\text { (i) } & * \text { (Pilli) mara } & \text { maSa l-ulaad Hilwe } \\ \text { the-woman } & \text { that with the-children pretty }\end{array}$

'The woman who is with the kids is pretty.'

29 (69) looks like Reverse Predication in the sense of Den Dikken (2006), where the predicate is generated in spec $\mathrm{RP}$ and the subject is in the complement of $\mathrm{Rel}^{\circ}$. While we obviously adopt the syntax of reverse predication, below we interpret RP in (69) as ApplP, rather than a syntactic reversal. While Den Dikken (2006) does suggest that reverse predications may have special semantic properties (in beautiful as a dancer for example, dancer is interpreted as an attribute, rather than a fully referential expression), we take the interpretive effects observed in Bare Inversion to point to the argument status of the specifier. 
ambiguous between an inalienable interpretation, derived from (69), and a Temporary Locative interpretation, derived by fronting of $\mathrm{PP}_{\mathrm{LOC}}$ from the complement of $\mathrm{Rel}^{\mathrm{O}}$, as in the derivation in (66). Both predictions are confirmed:

a. kaan $\quad$ ind mona tlat ulad

WAS.3SG.M at Mona three kids

'There were three kids in Mona's company.'

'Mona had three kids.'

b. kaan maia mona taw?am

WAS.3SG.M with Mona twins

'There were some twins in Mona's company.'

'Mona was pregnant with twins.'

A copula realized in a topicalization configuration, on the other hand, should keep the restriction to Temporary Locative interpretation with humans, since here PP fronts necessarily from the complement in RP. This is confirmed in (71):

a. Sind mona knan $_{1}$ flat ulaad $\mathrm{t}_{1}$

at Mona WAS.3SG.M FIIH three kids

'In Mona's company there were three kids.'

b. maia mona kaan fiih taw?am

with Mona $\quad$ WAS.3SG.M FIIH twins

'With Mona there were twins.'

Topicalization of $l a$-DP is expected to preserve the Part-Whole reading given its DP-internal source. With fiih merged in SpecIP to check EPP, la-DP may extract from within DP directly to the topic position in SpecCP. This is confirmed in (72): 
Deconstructing Possession

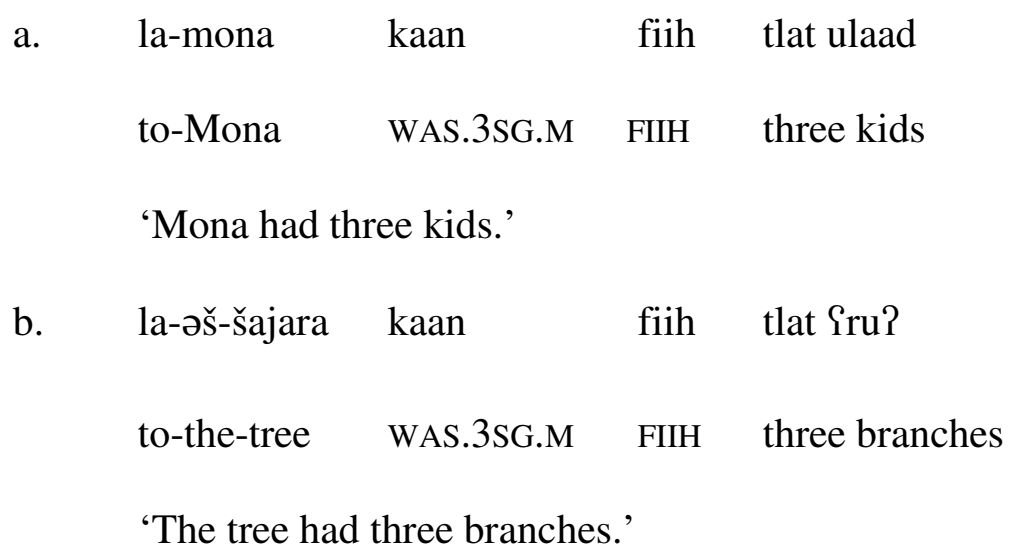

Thus, the special syntax associated with Bare Inversion combined with the analysis of obligatory copulas derives the distribution of interpretations across construction types in (70), (71), and (72). Furthermore, the contrast in the availability of the Part-Whole interpretation in topicalization, in (71) and (72), supports our claim that the prepositional types in (70) and (71) necessarily have a clausal source, while $l a-\mathrm{DP}$ is an argument within a containing DP. Coupled with the assumption that topicalization from SpecIP is highly restricted, we derive the interpretive effects above from the fact that topicalization cannot be fed by Bare Inversion, though it can be fed by sub-extraction of $l a$-DP from its containing DP.

\subsubsection{Enter the Applicative}

With this much established, we turn to discuss the RP structure of Bare Inversion in more detail. We have suggested that RP in (69) must have Sind / ma 9 a PP in its specifier, and the DP in the complement of $\operatorname{Rel}^{\circ}$. This is the reverse of what we find in ordinary locatives, where the predicative PP is complement of $\mathrm{Rel}^{\mathrm{O}}$. That the basic structure of Bare Inversion should be distinct has been independently motivated by the syntax, further supported by the special interpretive restriction found when the complement to $\mathrm{P}^{\mathrm{o}}$ is human. As shown in (60)-(62) above, for Sind / ma Ya PPs, Bare Inversion, and only Bare Inversion, forces an inalienable interpretation with human PP. 
The shift in interpretation suggests that here PP is not, in fact, an ordinary locative PP in canonical predicative position. Neither could the configuration of RP in (69) be easily understood as a case of 'reverse predication' in the sense of Den Dikken (2006), where the predicate is generated in SpecRP and the subject is in the complement of $\operatorname{Rel}^{\mathrm{O}}$, since a simple reversal would fail to account for the shift in interpretation and for the restriction to a subset of PPs.

We propose that Sind and ma Sa PPs, and only Sind / ma Sa PPs, can be generated in SpecRP due to their stativity combined with the underspecified location they denote. In terms of the applicative typology developed in Pylkkänen (2008) and Cuervo (2003), Sind and ma Ya are akin to AT applicatives (as opposed to the dynamic applicatives TO and FROM). Since only AT applicatives are found in statives, and locative and possessive clauses are stative, the restriction to Sind and ma 9 a follows from an applicative analysis of RelP, where the abstract head $\operatorname{Rel}^{\circ}$ is realized as applicative (abstract) AT: ${ }^{30}$

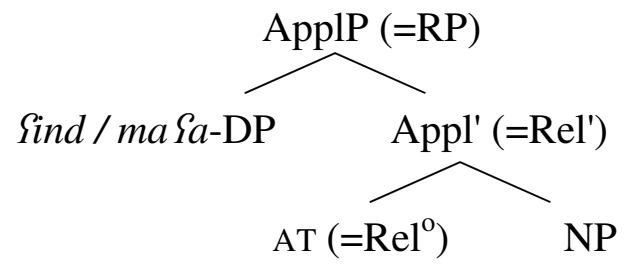

While (73) may recall the clausal analysis of Part-Whole given in Hornstein et al. (1995), it is actually distinct. On our analysis, Part-Whole necessarily has a DP-internal source, and it is only within DP that a functional noun takes a Whole as its argument, whether human or non-human. The applicative structure in (73), on the other hand, does not depend on the head of NP being functional in any sense, since PP combines with AT, and not with NP directly, just like a DP

\footnotetext{
${ }^{30}$ Note that the applicative head is abstract, with Sind and ma $9 a$ as part of the constituent within the specifier, correlating with the fact that in Topicalization it fronts as a constituent. We return to this in more detail below.
} 
subject is an argument of Voice, not of VP (Kratzer 1996). A functional noun is not required with humans or with non-humans. When the PP contains a non-human, the interpretation remains strictly Locative. We find no restriction to a functional head noun which would ensure Part-Whole as it does with $l a-\mathrm{DP}$ :

(74) a. Sind əš-šajara tlat @̌̌uuš

AT the-tree three nests

'There are three nests by/near the tree.'

b. \#la-əš-šajara tlat ९̌šuš

to-the-three three nests

c. la-əš-šajara tlat Sru?

to-the-tree three branches

'The tree has three branches.'

The contrast in the necessity of a functional noun with non-humans in (74) can be seen to correlate with the interpretation of a human PP in topicalization: while inalienable readings persist for $l a$-DP, they are neutralized for Sind / maSa PPs; both follow from the fact that the inalienable reading does not have a DP-internal source. We are proposing, then, that inalienable possession has two sources: a DP-internal function-argument relation, which equally covers nonhumans, and an applicative structure, where only the human subtype of Part-Whole, i.e. inalienable possession, is encountered.

We take the interpretive restriction to humans in Bare Inversion in PA to follow from the syntax and semantics of applicatives. Our implementation of $\operatorname{Rel}^{\circ}$ as a stative applicative head derives the clausal structure of alienable and inalienable possession from independently motivated grammatical ingredients: the asymmetry of the Small Clause, the category-neutral 
status of $\mathrm{Re}^{\mathrm{O}}$, and the syntax of applicatives. The novelty of our approach lies in the projection of an ApplP in the absence of any verbal structure. This possibility, however, is already implicit in the division into high and low applicatives proposed in Pylkkänen (2008): high applicatives are licensed above the verbal root and independently of it, while low applicatives are within the VP and take the possessed DP as direct complement. The typology is further refined in Cuervo (2003), where the low applicative entails possession and the high applicative is necessarily stative, denoting temporary location at the time of the event (with possession inferred, for humans, not entailed). The absence of verbal structure simply means that the division is neutralized and ApplP in (73) can do double duty: as a high applicative, ApplP is introduced independently of a verbal root and denotes Temporary Location at the time of the event, and alienable possession can be inferred, alongside Temporary Location, when its specifier is human. Due to the absence of a root VP, however, AT necessarily has DP as its direct complement. With humans in the specifier of ApplP, possession will be entailed, giving rise to inalienable possession when the head noun happens to denote a function. In brief, the implementation of RP as ApplP is what restricts the PPs in Bare Inversion to the stative, underspecified locative PPs which we actually find (whether human or not), whereas the absence of VP and, as a consequence, the ambiguity of ApplP produces inalienable possession with humans, while still allowing stative not-necessarily human PPs to denote temporary locations.

\section{English}

A similar dual analysis of inalienable possession may extend to English. We have seen in sections 2 and 3 that in the context of copular BE, English distinguishes Part-Whole, both human and non-human, from Temporary Location. We take that distinction to correspond to the division 
between DP-internal Part-Whole, and the projection of Temporary Locative PP as complement to $\mathrm{Rel}^{\mathrm{O}}$. In the context of HAVE, however, English, like PA, shows a special restriction to humans. Humans may be interpreted as Temporary Locations, without having the locative syntax associated with non-human Temporary Locations (Belvin 1993; Déchaine et al. 1994; Harley 1998). The Locative construal in (75b), which, unlike (75a), cannot be interpreted as a Whole argument of a functional Part, keeps the preposition in situ, followed by a bound pronoun. The human subject of (75c) similarly denotes a Temporary Location, as seen by the possibility to have a possessor embedded in DP. Here the resumptive strategy, though possible, is not required:

(75) a. The tree has many branches

b. The tree has many nests *(in it)

c. Mary has Paul's books (on her shelf)

We take the resumptive strategy to signal both the basic positioning of the underlying locative PP and the absence of movement to subject from this position, on a par with the standard analysis of resumptive pronouns in relative clauses. The necessity of this strategy in the locative (75b) means that movement is impossible, while in (75c) movement to subject position must be possible on the version in which there is no PP. On the version with the pronoun containing PP, movement is impossible, just like (75b). This suggests a clear analogy with PA: (75c) with a human PP is ambiguous, just like Sind-DP is ambiguous between a canonical Predicative Locative structure and an applicative structure. In English, movement of $\mathrm{PP}_{\mathrm{LOC}}$ to SpecIP is blocked just as it is for $\mathrm{PP}_{\mathrm{LOC}}$ in Bare Inversion in PA. Assuming that the movement-allowing version of $(75 \mathrm{c})$ is related to the applicative analysis developed for PA, we can conclude, first, that the applicative structure is more restricted in English than it is in PA, and applies only to humans. 
A further difference between English and PA has to do with the severity of the constraint against fronting a predicate locative PP in a copular construction. While in PA fronting of a pure locative PP is facilitated by the realization of the copula and domain extension, the introduction of HAVE is not nearly as useful in (75c), where the copula is present but $\mathrm{PP}_{\mathrm{LOC}}$ movement is nevertheless still blocked. We could of course take this to imply that English HAVE does not serve the same domain-extending purpose as the PA copula. But if not, then HAVE would not be the equivalent of PA copular BE (or, for that matter, English BE) plus an incorporated head (Benveniste 1966; Freeze 1992, etc.). If anything, an additional incorporated head should provide more movement options, not less. The conclusion that English HAVE is not BE endowed with an additional head undermines the typological generalization across HAVE and BE, and so should be avoided if possible. ${ }^{31}$ Fortunately, it also seems not to be empirically justified in this domain, since the problem with $\mathrm{PP}_{\mathrm{LOC}}$ inversion in English copular sentences is observed also with BE. While equative copular constructions, where the post-copular expression includes the noun place and the like, are possible (76a), and so is Locative Inversion with lexical verbs, in (76c) (Stowell 1981; Bresnan 1994), $\mathrm{PP}_{\mathrm{LOC}}$ inversion in copular constructions is degraded:

(76) a. Under the bed is a good place to hide

b. *Under the bed are your red shoes

c. On the mantelpiece stood an impressive Haitian sculpture

d. $\quad *$ On the mantelpiece was an impressive Haitian sculpture

The problem with $(75 \mathrm{c})$, then, cannot be locality per se, since BE is of no particular use here either. We propose therefore that the cross-linguistic difference in the availability of copular $\mathrm{PP}_{\mathrm{LOC}}$ inversion has more to do with the difference in the agreement systems of English and PA.

\footnotetext{
${ }^{31}$ Not that this view of HAVE is completely uncontroversial. See Law (1994); Mahajan (1994); Hoekstra (1994); Nash (1998) for alternative views of HAVE.
} 
Following Den Dikken (2006), English licenses Predicate Inversion only if the inverted predicate contains a null category to be licensed in SpecIP. It follows then, that since it does not contain a null element, $\mathrm{PP}_{\mathrm{LOC}}$ cannot be fronted in the English copular construction. In PA, on the other hand, locative PP can raise to SpecIP, modulo locality and the repair provided by the copula. Why, then, is it possible in PA but not in English? Following Collins (1997), we assume that considerations of economy favor overt raising of the subject DP over the combination of PP raising and covert feature checking / Agree with the in situ subject. Crucially, however, $\mathrm{PP}_{\mathrm{LOC}}$ inversion in PA is based on the poor agreement paradigm, and so, quite simply, there are no phifeatures remaining to be checked against the in situ subject. ${ }^{32}$ Since there is no additional step to worry about, considerations of economy become moot. Assuming, with Den Dikken (2006), that the need to license a null category overrides considerations of economy in English, the possibility to front a full PP, modulo locality, follows from the nature of poor agreement in PA. This leaves the Freezian account of HAVE intact, and so it is still a potential aid in the circumvention of minimality in (75b).

The question to address now is why fronting of a locative to SpecIP should be allowed with humans, i.e. (75b) vs. (75c). On the analysis we have developed, the restriction to humans follows from an applicative structure. Recent related work on locatives, possession, and experiencers (Harley 1998; Landau 2005; Cuervo 2003; Adger \& Ramchand 2007) has also isolated the human aspect of location, relating it to the notion of 'experiencer', where the latter is understood in terms of human location. Human locations, on this view, are distinct from ordinary locations in the sense that they also qualify as experiencers. For Pylkkänen (2008), Cuervo

\footnotetext{
${ }^{32}$ Here and throughout, we have left the Case-checking procedure entirely open. Within the combination of claims regarding the relation of agreement and scope, the absence of a null expletive, and EPP checking at PF, we are lead to conclude that Nominative Case assignment, at least in PA, plays no necessary syntactic role (cf. Borer 1986, Marantz 1991, and more recently Bobalijk 2008).
} 
(2003), and Adger \& Ramchand (2007), this has meant, concretely, that (at least a subset of) human locations, may, in some languages, be realized as high applicatives. English, however, does not have high applicatives in verbal structures. ${ }^{33}$ We propose a 'derived applicative' for English possessive HAVE: the human location starts out as a predicative PP, where $\mathrm{P}^{\mathrm{o}}$ is overt AT. We assume with Den Dikken (2006) that Predicate Inversion is possible in copular constructions only if $\mathrm{P}^{\mathrm{o}}$ is empty, i.e. $\mathrm{PP}$ is 'beheaded'. We propose then that $\mathrm{P}^{\mathrm{o}}$ raises to $\operatorname{Rel}^{\mathrm{o}}$, allowing $\mathrm{PP}$ to be targeted by SpecIP. Further movement of $\mathrm{Rel}^{\circ}$ to $\mathrm{F}^{\mathrm{o}}$, allows PP to cross the subject in SpecRP on its way to SpecFP:

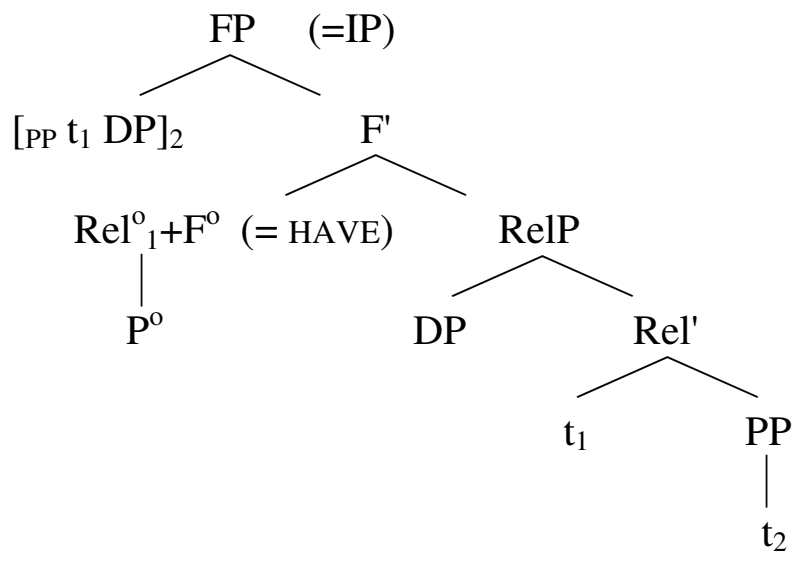

We derive the applicative structure of (73) via the mechanics of Predicate Inversion independently developed by Den Dikken (2006). The only difference between English and PA is that $\mathrm{P}^{\mathrm{o}}$ incorporates into $\mathrm{Rel}^{\mathrm{o}}$, an operation which allows inversion by freeing the construction from economy-based competition between DP and PP. But besides this, incorporation of $\operatorname{Rel}^{\mathrm{O}}$ into $\mathrm{F}^{\mathrm{o}}$ is identical to its counterpart in PA and in English BE. Since the incorporee is a preposition, $\mathrm{F}^{\mathrm{o}}$ spells out as HAVE, rather than BE. We see no reason not to take FP in (77) to be IP, and conclude that the subject of English non-locative HAVE is derived via A-movement, either

\footnotetext{
${ }^{33}$ Corresponding to the absence of benefactives in unergatives.
} 
Deconstructing Possession

from within DP, in the case of Part-Whole, or from RelP, where humans, alienable, and inalienable possession are involved.

\section{Conclusions}

The array of ingredients realized overtly in PA strongly supports the decomposition of possession into a variety of syntactic configurations associated with distinct meanings. The picture which emerges is partly familiar and partly new. The subject in possessive clauses is a derived subject in the alienable, inalienable, and Part-Whole relations, but not necessarily in the non-human locative relation, where it is governed by considerations of economy and variation in the morpho-syntax of agreement. We have also argued that clausal possession has a DP as its source, but only on the Part-Whole construal, drawing on previous work on the DP-internal semantics of possession. The examination of differences between Part-Whole and Temporary Location in EPP satisfaction within the poor agreement paradigm has led, in turn, to the postulation of a third source. Bare Inversion structures in PA, as we have shown, are both free from the locality constraints governing ordinary locative PP-fronting, and also feature a special restriction related to humans, and a new key to understanding the blurring of location and possession when it comes to humans. The combination of distinct syntax and distinct semantics provides the basis for an underlying applicative structure in the absence of a lexical verb. The applicative structure, on our conception, may be basic or derived by head-movement, as it is in English, and it may be headed by an overt preposition or simply contain an abstract stative head, as it does in PA. If we are correct, and these possibilities do generalize to other contexts, the difference between HAVE and BE may further reduce to the parametric realization of prepositions in ApplP. 


\section{Acknowledgements}

We thank audiences at IATL23 and CSSP5 for questions and comments. Special thanks to Marcel Den Dikken for insightful comments on an earlier draft, and to our informants, Hadil Karawani, Hanin Karawani, Khawla Rihani \& Shireen Siam, for their insight into the data and patience with our questions. All errors remain our own.

\section{References}

Adger, D. \& Ramchand, G. 2007. Psych nouns and predication. In A-R. Deal et al. (eds.)

Proceedings of NELS 36. GLSA, University of Massachusetts, Amherst.

Åfarli, Tor. 2007. Invisible phi-features do not exist: Evidence from expletive constructions in English and Norwegian. Talk given at the workshop The Sound Patterns of Syntax, Ben Gurion University of the Negev.

Bailyn, J. 2004. Generalized Inversion. Natural Language and Linguistic Theory 20: 1-50.

Baron, I., Herslund, M. \& F. Sorensen. 2001. Dimensions of Possession. Typological Studies in Language 47. Amsterdam: John Benjamins Publishing Company.

Belvin, R. 1993. The two causative haves are the two possessive haves. MIT Working Papers in Linguistics 20: 19-34.

Benveniste, E. 1966. Problèmes de linguistique générale 2. Paris : Gallimard.

Biberauer, T. \& I. Roberts. 2008. Cascading parameter changes: internally-driven change in Middle and Early Modern English. In: Eythórsson, Th. \& J.T. Faarlund (eds.). Grammatical Change and Linguistic Theory: the Rosendal Papers. Amsterdam: John Benjamins Publishing Company. pp. XXXX 
Deconstructing Possession

Bobalijk, J. 2008. Where's Phi? Agreement as a Post-Syntactic Operation. In Adger, D., Béjar, S.

\& Harbour, D. (eds.) Phi-Theory: Phi features across interfaces and modules. Oxford: Oxford University Press. pp. XXXXX

Bobalijk, J. D. \& H. Thráinsson. 1998. Two heads aren't always better than one. Syntax 1: 37-71.

Borer, H. 1986. I-Subjects. Linguistic Inquiry 17: 375-416.

Bresnan, J. 1994. Locative Inversion and the architecture of Universal Grammar. Language 70, $72-131$.

Burge, T. 1972. Truth and Mass Terms. Journal of Philosophy, 69.

Cardinaletti, A. \& I. Roberts. 2002. Clause structure and X-second. In G. Cinque (ed.) Functional

Structure in IP and DP: The cartography of syntactic structure, Volume 1. pp. 123-166. New

York/Oxford: Oxford University Press.

Chomsky, N. 1986. Barriers. Cambridge, MA: MIT Press.

Chomsky, N. 1995. The Minimalist Program. Cambridge, MA: MIT Press.

Chomsky, N. 2000. Minimalist inquiries: The framework. In Martin, R., Michaels, D. \& J.

Uriagereka (eds.). Step by Step: Essays on Minimalist Syntax in Honor of Howard Lasnik.

Cambridge, MA: MIT Press. pp. 89-115.

Collins, C. 1997. Local Economy. Cambridge, MA: MIT Press.

Cowell, M.W. 1964. A Reference Grammar of Syrian Arabic. Washington D.C.: Georgetown

University Press.

Cuervo, M.C. 2003. Datives at Large. PhD Dissertation. MIT.

Déchaine, R.M. 1993. Predicates Across Categories. PhD Dissertation. University of Massachusetts at Amherst. 
Déchaine, R.M, T. Hoekstra \& J. Rooryck. 1994. Augmented and non-augmented HAVE. In L.

Nash \& G. Tsoulas (eds.), Proceedings of Langues et Grammaire 1. Paris: Université Paris 8, Saint-Denis.

Den Dikken, M.1995. Copulas. Paper presented at GLOW Tromsø; unpublished manuscript, Vrije Universiteit Amsterdam/HIL.

Den Dikken, M. 2001. 'Pluringulars', pronouns, and quirky agreement. The Linguistic Review 18: $19-41$.

Den Dikken, M. 2006. Relators and Linkers: The Syntax of Predication, Predicate Inversion and Copulas. Cambridge, MA: MIT Press.

Den Dikken, M. \& A. Næss. 1993. Case dependencies: The case of Predicate Inversion. Linguistic Review 10, 303-336.

Diesing, M. 1992. Bare plural subjects and the derivation of logical forms. Linguistic Inquiry 23: 353-380.

Dobrovie-Sorin, C. 2005. Genitives and determiners. In Jiyung Kim, Yuri A. Landers \& Barbara H. Partee (eds), Possessive and Beyond: Semantics and Syntax, University of Massachusetts Occasional Papers in Linguistics, 29, pp. 115-132.

Doron, E. 1983. Verbless Predicates in Hebrew. Unpublished doctoral dissertation, University of Texas at Austin.

Dowty, D. \& C. Barker. 1992. Non-verbal thematic proto-roles. Proceedings of NELS 23. Amherst, MA: GSLA. pp. 49-62.

Fassi Fehri, A. 1993. Issues in the Structure of Arabic Clauses and Words. Dordrecht: Kluwer. Fox, D. 2000. Economy and Semantic Interpretation. Cambridge, MA: MIT Press. 
Deconstructing Possession

Freeze, R. 1992. Existentials and other Locatives. Language 68: 553-595.

Godard, D. 1992. Extraction out of NP in French. Natural Language and Linguistic Theory 10: 233-277.

Guéron, J. 2006. Inalienable Possession. In M. Everaert., H. Van Riemsdijk, R. Goedemans \& B. Hollenbrandse, (eds.) The Blackwell Companion to Syntax. Blackwell Publishing. pp. 585-634. Harley, H. 1998. You're having me on! Aspects of have. In Guéron \& Zribi-Hertz, A. (eds.), $L a$ Grammaire de la possession. Université Paris X, Nanterre: PUBLIDIX. pp. 195-226.

Heine, B. 1997. Possession. Cambridge: Cambridge University Press

Heller, D. 2002. Possession as a Lexical Relation: Evidence from the Hebrew Construct State. In L. Mikkelsen and C. Potts (eds.), WCCFL 21 Proceedings. Somerville, MA: Cascadilla Press. pp. 127-140.

Henry, A. 1995. Belfast English and Standard English: Dialect variation and parameter setting. Oxford: Oxford University Press.

Henry, A. \& S. Cottell. 2007. A new approach to transitive expletives: Evidence from Belfast English. English Language and Linguistics 11: 279-299.

Heycock, C. 1994. The internal structure of Small Clauses. Proceedings of NELS 25. Amherst, MA: GLSA. pp. 223-238.

Hoekstra, T. 1994. HAVE as BE plus or minus. In G. Cinque, J. Koster, J.-Y. Pollock, L. Rizzi and R. Zanuttini (eds.) Paths towards Universal Grammar: studies in honor of Richard S. Kayne. Georgetown studies in Romance Linguistics. pp. 199-215.

Hoekstra, T. \& R. Mulder. 1990. Unergatives as copular verbs: locational and existential predication. The Linguistic Review 7:1-79. 
Deconstructing Possession

Holmberg, A. 2000. Scandinavian Stylistic Fronting: How Any Category Can Become an

Expletive. LinguisticInquiry 31: 445-483.

Hornstein, N.S. 1994. An Argument for Minimalism: The case of Antecedent Contained

Deletion. Linguistic Inquiry 25: 455-480.

Hornstein, N.S., Rosen, S. \& Uriagereka, J. 1995. Integrals.

http://www.ling.umd.edu/Courses/Ling819/Papers/Integrals.pdf

Hoyt, F. 2000. Agreement, Specificity Effects, and Phrase Structure in Rural Palestinian Arabic Existential Constructions. MA Thesis. Cornell University.

Jensen, P.A. \& Vikner, C. 2004. The English prenominal genitive and lexical semantics. In Possessives and Beyond: Semantics and Syntax (UMOP 29), J.-Y. Kim, Y. A. Lander \& B. H. Partee (eds.). Amherst, MA: GLSA Publications. pp. 3-27.

Jonas, D. \& J. Bobalijk. 1996. Subject positions and the roles of TP. Linguistic Inquiry 27: 195236

Johnson, K. \& S. Tomioka. 1997. Lowering and mid-size clauses, Proceedings of the Tübingen Workshop on Reconstruction, Tübingen, Germany.

Kayne, R. 1993/2000. Towards a Modular Theory of Auxiliary Selection. Parameters and Universals. Oxford: Oxford University Press.

Kratzer, A. 1996. Severing the external argument from its verb. In J.

Rooryck \& L. Zaring, (eds.), Phrase Structure and the Lexicon. Dordrecht: Kluwer. pp. 109137.

Kuno, S. 1971. The position of locatives in existential sentences. Linguistic Inquiry 2: 333-378.

Landau, I. 2005. The Locative Syntax of Experiencers. Ms., Beer Sheva: Ben Gurion University 
Deconstructing Possession

Landau, I. 2007. EPP Extensions. Linguistic Inquiry. 38: 485-523.

Lasnik, H. \& M. Saito. 1992. Move a: Conditions on its application and output. Cambridge, MA: MIT Press.

Law, P. 1994. Remarques sur la construction existentielle en haïtien. Revue québécoise de linguistique 23:1.

Longobardi, G. 2000. "Postverbal" subjects and the mapping hypothesis. Linguistic Inquiry 31: 691-702.

Mahajan, A., 1994, The Ergativity Parameter: have-be alternation, word order and split ergativity. Proceedings of NELS 24. pp. 317-331.

Marantz, A. 1991. Case and Licensing. In Proceedings of ESCOL, 234-253. Cornell Linguistics Club. Republished in Reuland (2000) Arguments and Case: Explaining Burzio's Generalization. Amsterdam/Philadelphia: John Benjamins. pp. 11-30.

Marantz, A. 1993. Implications of asymmetries in double object constructions. In S.

Mchombo (ed.), Theoretical aspects of Bantu grammar. Stanford: CSLI Publications, pp. 113150.

McCloskey, J. \& K. Hale. 1984. On the syntax of person-number inflection in Modern Irish. Natural Language and Linguistic Theory 1: 487-533.

Mohammad, A. M. 1998. The Syntax of Indefinite Subjects in Equative Sentences in Palestinian Arabic. The Semitic Archive: http://www.usc.edu/schools/college/semitic/private/pdf/sisespa.pdf. Mohammad, A. M. 2000. Word Order, Agreement and Pronominalization in Standard and Palestinian Arabic. Amsterdam: John Benjamins Publishing Company.

Moro, A. 1990. There-raising: Principles across levels. Paper presented at GLOW Cambridge. 
Moro, A. 1997. The raising of predicates: Predicative nominals and the theory of clause structure. Cambridge University Press.

Nash, L. 1998. A propos de "être" et "avoir" en géorgien. In Rouveret, A. (ed.), « Être » et «Avoir » : syntaxe, sémantique, typologie. Presses Universitaires de Vincennes, Saint-Denis. pp. 171-196.

Ouhalla, J., 1998, Possession in Sentences and Noun Phrases. www.usc.edu/dept/LAS/linguistics/semitic/pdf/ur.pdf

Partee, B. H. 1999. Weak NP's in Have Sentences. Reprinted in Partee, B. H. H. 2004. Compositionality in Formal Semantics: Selected Papers by Barbara H. Partee. Oxford: Blackwell Publishing, pp. 282-291.

Partee, B.H. \& Borschev, V. 2004. Genitives, relational nouns, and argument modifier ambiguity. In: E. Lang, C. Maienborn and C. Fabricius-Hansen (eds.), Modifying Adjuncts. Series: Interface Explorations. Berlin and New York: Mouton de Gruyter. pp. 67-112.

Pylkkänen, L. 2008. Introducing Arguments. Cambridge, MA: MIT Press.

Rapoport, T. 1987. Copular, Nominal and Small Clauses: A Study of Israeli Hebrew. PhD

Dissertation, MIT.

Rizzi, L. 1990. Relativized Minimality. Cambridge, MA: MIT Press.

Rizzi, L. \& Shlonsky, U. 2006. Satisfying the Subject Criterion by a Non Subject:

English Locative Inversion and Heavy NP Shift. In Frascarelli, M. (ed.) Phases of Interpretation. Berlin: Mouton de Gruyter. pp. 341-361.

Rouveret, A. 1991. Functional Categories and Agreement. The Linguistic Review 8: 353-387.

Sauerland, U. \& P. Elbourne. 2002. Total Reconstruction, PF Movement and Derivational Order. Linguistic Inquiry 33: 283-319. 
Sichel, I. 1997. Two pronominal copulas and the Syntax of Hebrew Nonverbal Sentences. R.

Blight \& M. Moosally (eds.) Texas Linguistics Forum 38: 295-306

Stowell, T. 1981. Origins of Phrase Structure. PhD Dissertation, MIT.

Szabolcsi, A. 1983. The possessor that ran away from home. The Linguistic Review 3: 89-102.

Szabolcsi, A. 1994. The Noun Phrase. In Kiefer, F \& Kiss, K. (eds.) Syntax and Semantics 27:

The Syntactic Structure of Hungarian. San Diego, CA: Academic Press. pp. 179-274

Vergnaud, J.R. \& M.L. Zubizaretta. 1992. The definite determiner in French and in English.

Linguistic Inquiry 23: 595-652. 